\title{
Thermocapillary Pumping of Discrete Drops in Microfabricated Analysis Devices
}

\author{
Timothy S. Sammarco and M ark A. Burns \\ D ept. of Chemical E ngineering, U niversity of M ichigan, A nn A rbor, M I 48109
}

\begin{abstract}
A nonmechanical pumping mechanism, thermocapillary pumping (TCP), is described for moving nanoliter- and picoliter-sized drops of liquid within microfabricated flow channels. In TCP, one end of a single drop is heated to create a surface tension difference between the ends of the drop. The induced surface tension difference causes a capillary pressure difference between the two drop ends and results in drop motion. TCP velocities of up to $20 \mathrm{~mm} / \mathrm{min}$ were measured for several liquids at temperature differences between 10 and $70^{\circ} \mathrm{C}$. An expression developed for TCP velocity yields predictions that agree with experimental velocities within corresponding uncertainty limits. Several techniques for assisting TCP are also suggested when contact angle hysteresis, the major factor limiting TCP velocities, is too large. These techniques include using surface treatments to reduce the contact angle hysteresis, converging channels to offset hysteresis, or an applied pressure to assist in movement.
\end{abstract}

\section{Introduction}

In the past few years, microfabrication has emerged as a promising technology for miniaturizing and integrating chemical analysis systems. Potential applications of such technology include chemical process monitoring, medical diagnostics, and environmental testing (Burns et al., 1996, 1998; Burke et al., 1997; Cefa et al., 1994; van der Berg and Bergvald, 1995; E ffenhauser et al., 1994; H arrison et al., 1993; R amsey, 1997; A nderson et al., 1997; M arshall and Hodgson, 1998). For simple chemical sensing, little or no sample preparation is needed resulting in single-step probe-like systems (Patel et al., 1996; Walton et al., 1997). For multiple step chemical analysis, however, the sample must often be taken through a sequence of operations in order to elucidate the desired information. For instance, protocols for DNA analysis may include operations such as pipetting of discrete liquid volumes, mixing of sample and reagents, reaction of sample and reagents, and separation and detection of reaction products. Since these operations are often sequential, they are conducive to integration into a single microfabricated device (Burns et al., 1996, 1998). In addition to simplifying chemical analysis through integration, the inherent miniaturization

Correspondence concerning this article should be addressed to M. A . Burns. from microfabrication would reduce chemical costs by lowering sample volumes by several orders in magnitude.

$M$ uch of the effort to microfabricate chemical analysis systems has concentrated on the development of the individual components needed for chemical analysis rather than the complete integration of the analysis components within a single microfabricated device. For instance, researchers have constructed and tested microfabricated devices for performing sample injection ( $\mathrm{H}$ andique et al., 1997; $\mathrm{F}$ an and $\mathrm{H}$ arrison, 1994), biochemical reactions (Burns et al., 1996; Srinivasan et al., 1997; Northrup et al., 1993), chromatographic (Hannoe et al., 1997), and electrophoretic separations (W ebster and M astrangelo, 1997; Burns et al., 1996; $\mathrm{H}$ arrison et al., 1993), and sample detection (W ebster and $M$ astrangelo, 1997). Combining these basic components in a microfabricated format will require that each of these analysis steps be connected via a network of microfluidic channels. By fabricating an integrated pumping system within this channel network, the basic operations of chemical analysis can be combined into a single, self-contained microfabricated device.

$M$ icrofluidic pumping systems for liquid transport in microfabricated channels can be classified as being either mechanical or nonmechanical. M echanical pumping systems are typically based upon the deflection of a thin membrane into a 
pumping chamber or channel. The deflected membrane forces liquid through the channels to create a pumping action. Membrane actuation in these systems can be done electrostatically (Zengerle et al., 1992), piezoelectrically (Shoji and Esashi, 1994; van L intel, 1988; Smits, 1990), or thermoneumatically (Folta et al., 1992; van de Pol et al., 1990). By using multiple membrane chambers, a peristaltic pumping action can be achieved (Folta et al., 1992; Smits, 1990). Alternatively, a reciprocating type pump can be constructed by combining two check valves with a single membrane actuator (van de Pol, 1990; van Lintel, 1988). These mechanical systems are designed for operating on continuous liquid streams; consequently, they may be well suited for simple continuous monitoring applications such as in liquid chromatography.

Nonmechanical pumping mechanisms include electrohydrodynamic pumping (EHP) (Bart and Tarrow, 1990), electroosmotic flow (EOF) (M anz et al., 1995), and electrowetting (Beni and Tenan, 1981). In electrohydrodynamic pumping (Bart et al., 1990; Fuhr et al., 1994), a traveling electric field wave is applied with open electrodes and used to induce a bulk liquid flow with velocities on the order of several hundred microns per second (Fuhr et al., 1994). EHP is best suited for nonconductive or low conductivity liquids but reportedly has been adapted for electrolyte solutions ( $F$ uhr et al., 1994). In electroosmotic flow, the motion of an electric double layer relative to a charged channel surface drags fluid in the direction of ion transport and induces a bulk liquid flow. This phenomenon, which is common in capillary zone electrophoresis, is driven by the attraction of the electric double layer to electrodes bounding the channels ends. In electrowetting, an electric potential is applied to a surface electrode located beneath a meniscus of a discrete drop of an electrolyte solution. This surface potential creates an electric double layer (acting as a parallel plate capacitor) that can be used to control capillary pressures and induce fluid motion. Note that electrowetting, like EHP, requires the use of open electrodes.

We have developed a nonmechanical surface-tensiondriven pumping system for moving discrete liquid drops within microfabricated channels that does not utilize open electrodes. As fluidic channel dimensions decrease, surface tension forces increase relative to the gravitational, viscous, and inertial forces. For example, a drop of water moving at $1 \mathrm{~cm} / \mathrm{s}$ inside a $100 \mu \mathrm{m}$ diameter capillary tube yields the following dimensionless numbers

[Bond Number (Bo) $]^{-1}$

$$
=\frac{\text { Surface Tension Force }}{\text { G ravitational Force }}=\frac{\sigma}{\rho \mathrm{gd}^{2}} \approx 10^{3}
$$

[Capillary Number (Ca) $]^{-1}$

$$
=\frac{\text { Surface Tension Force }}{\text { V iscous F orce }}=\frac{\sigma}{\mu \mathrm{U}} \approx 10^{4}
$$

$[\text { W eber } N \text { umber }(\mathrm{We})]^{-1}$

$$
=\frac{\text { Surface Tension Force }}{\text { Inertial Force }}=\frac{\sigma}{\rho \mathrm{dU}^{2}} \approx 10^{4}
$$

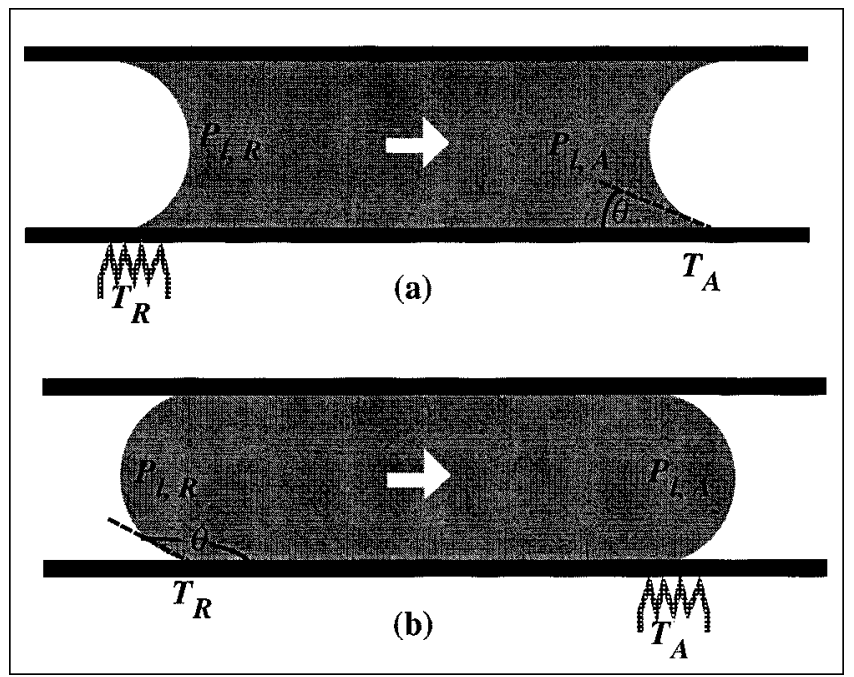

Figure 1. Thermocapillary Pumping (TCP) of drops of liquid in (a) hydrophilic $\left(\theta<90^{\circ}\right)$ and (b) hydrophobic $\left(\theta>90^{\circ}\right)$ channels.

D rop motion results from heating-induced capillary pressure differences between the ends of the drop. Heating occurs at the receding end in hydrophilic systems (a) or at the advancing end in hydrophobic systems (b).

where $\sigma$ is the surface tension, $\rho$ is the liquid density, $g$ is the gravitational constant, $d$ is a characteristic length (channel height), $\mu$ is the liquid viscosity, and $U$ is the characteristic velocity. The large values of these dimensionless numbers indicate the dominating influence of surface forces at small scales relative to the other forces that influence liquid behavior. Controlling these surface forces can serve as a drive mechanism for a simple liquid pumping system.

This article presents a theoretical basis for such a pumping mechanism and develops an expression for its steady-state pumping velocity. N ext, the pumping mechanism is tested using microfabricated flow devices constructed from silicon and glass. A theoretical analysis is presented to extend and enhance the use of this mechanism in various systems.

\section{Theoretical Development \\ Thermocapillary pumping}

A discrete liquid sample within a fluidic channel contains two menisci (Figure 1), each with an associated radius of curvature. The curvature of the meniscus produces a pressure difference between the two phases called capillary pressure that can be defined by the following form of the YoungL aplace equation

$$
\mathrm{P}_{\mathrm{c}}=\mathrm{P}_{\mathrm{g}}-\mathrm{P}_{\mathrm{l}}=\frac{\mathrm{G} \sigma \cos \theta}{\mathrm{d}} \text {. }
$$

In this equation, $P_{c}$ is the capillary pressure (see Probstein, 1989), $P_{g}$ is the interface pressure on the gaseous side, $P_{\mid}$is the interface pressure on the liquid side, $\theta$ is the contact angle [see de Gennes (1985) and Dussan (1979) for reviews] between the liquid and solid phases, $\sigma$ is the liquid surface 
tension, $d$ is the channel diameter (height), and $G$ is a constant specific to channel geometry $(G=4$ for circular, $G=2$ for slit-like, and $G \approx 2[1+$ height/width $]$ for square or rectangular).

Although E q. 4 was derived from a static force balance, the balance is a reasonable approximation for moving drops if the static contact angle is replaced by the dynamic contact angle (R ose and Heins, 1962; R illaerts and J 00s, 1979; K woK et al., 1996; Marmur, 1996; Schwartz and Eley, 1998), and inertial and shear forces are negligible compared to surface tension forces. Furthermore, the contact angle used in E q. 4 is based on a meniscus with a constant mean curvature (R ose and $\mathrm{H}$ eins, 1962), unlike the menisci formed by the motion of long gas bubbles through liquid filled channels (Bretherton, 1961).

Although a pressure difference exists between the liquid and gas phases across each interface, as shown in Figure 1, the liquid pressures between the ends are balanced $\left(\mathrm{P}_{1, \mathrm{R}}-\right.$ $\mathrm{P}_{\mathrm{I}, \mathrm{A}}=0$ ) and the drop remains stationary. By manipulating the surface tension on one side of a liquid drop, a pressure difference can be generated for liquid motion. This pressure difference can be produced by heating one drop interface because surface tension decreases linearly with meniscus temperature (J asper, 1972)

$$
\sigma=\mathrm{a}-\mathrm{bT}
$$

where $a$ and $b$ are positive empirical constants. We refer to this heat-induced, pressure-driven flow as thermocapillary pumping (TCP) (Burns et al., 1996). The appeal of a heat induced mechanism lies in the simplicity of its application within a microfabricated device. Furthermore, the device requires no moving parts, is self-contained, requires no open electrodes, and is applicable to discrete drops.

D rop motion by TCP occurs by heating either the receding interface of a hydrophilic drop $\left(\theta<90^{\circ}\right.$, Figure 1a) or the advancing interface of a hydrophobic drop $\left(\theta>90^{\circ}\right.$, Figure 1b). A liquid-phase pressure difference across the length of the drop is subsequently induced by the change in capillary pressure at the heated end. This induced pressure difference occurs even though both ends of the drop are exposed to an identical gas-phase pressure. TCP's nonreliance on an external gas-phase pressure difference eliminates the need for an external pressure source, thus yielding simple, self-contained devices. Furthermore, TCP is compatible with any channel surface that produces a curved liquid interface including silicon, glass, quartz, and various polymers.

\section{Pumping velocity}

Similar to Poiseuille flow through a pipe, TCP is the pressure-driven flow of a liquid contained within a closed channel. Consequently, the Poiseuille solution to the NavierStokes equations is used to quantify the resulting pumping velocity (D enn, 1980; R ose and Heins, 1962; Y arnold, 1938; West, 1911; R ichter et al., 1997)

$$
\nu=\left(\frac{d^{2}}{S \mu L}\right) \Delta P .
$$

In this expression $\nu$ is the average drop velocity, $\mu$ is the bulk liquid viscosity, $L$ is the drop length, $\Delta P$ is the internal liquid-phase pressure difference between the ends of the drop $\left(P_{I, R}-P_{I, A}\right)$, and $S$ is a constant specific to channel geometry [circular: $S=32$, square: $S=28.45$, and slit-like: $S=12$. The shape constant $S$ for rectangular channels of intermediate channel height to width ratios can be found in Green (1984). A lthough the systems described by E q. 6 are bound by a meniscus at each end, Poiseuille flow is expected since the streamlines depart from their normal parallel form only at the very ends of the drop. Consequently, as long as a sufficiently large drop-length-to-height ratio is maintained, Eq. 6 is valid for the drop. Rose and Heins (1962) found that with $\mathrm{L} / \mathrm{d}$ ratios exceeding 100 , their drops exhibited Poiseuille behavior. Note that the end correction to $L$ suggested by $Y$ arnold (1938) is not applied since $L / d$ is large and the correction is not expected to contribute significantly.

The pressure difference between the drop ends includes contributions from the thermally induced surface tension differences $\left(\Delta P_{c}\right)$, gravity $\left(\Delta P_{h}\right)$, and any external pressure source $\left(\Delta \mathrm{P}_{\mathrm{e}}\right)$

$$
\Delta \mathrm{P}=\mathrm{P}_{\mathrm{I}, \mathrm{R}}-\mathrm{P}_{\mathrm{l}, \mathrm{A}}=\Delta \mathrm{P}_{\mathrm{c}}+\Delta \mathrm{P}_{\mathrm{h}}+\Delta \mathrm{P}_{\mathrm{e}}
$$

These contributions are described by the following relationships

$$
\begin{aligned}
& \Delta \mathrm{P}_{\mathrm{c}}=\mathrm{P}_{\mathrm{C}, \mathrm{A}}-\mathrm{P}_{\mathrm{C}, \mathrm{R}}=\mathrm{G}\left[\left(\frac{\sigma \cos \theta}{\mathrm{d}}\right)_{\mathrm{A}}-\left(\frac{\sigma \cos \theta}{\mathrm{d}}\right)_{\mathrm{R}}\right] \\
& \Delta \mathrm{P}_{\mathrm{h}}=\rho \mathrm{gL} \sin \phi \\
& \Delta \mathrm{P}_{\mathrm{e}}=\mathrm{P}_{\mathrm{g}, \mathrm{R}}-\mathrm{P}_{\mathrm{g}, \mathrm{A}} .
\end{aligned}
$$

The subscript $A$ refers to the advancing meniscus of a moving drop, while $R$ refers to the receding meniscus (Figure 2); $P_{g, R}$ and $P_{g, A}$ are the gas-phase pressures at the receding and advancing ends of the drop, respectively, and $\phi$ is the angle the channel slants below the horizon in the direction of motion (Figure 2). Note that Eq. 8 describes the capillary

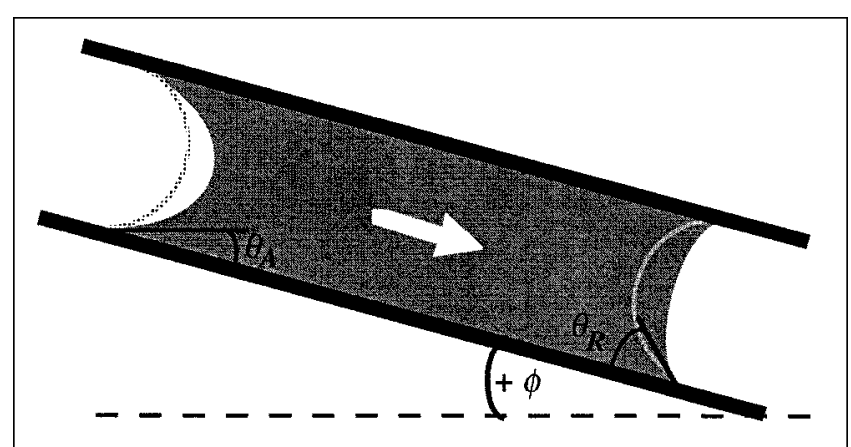

Figure 2. Contact angle hysteresis in a moving hydrophilic drop.

With hysteresis, the advancing contact angle exceeds the receding angle, thus, creating a resistance to drop motion. A Iso shown is the notation used for inclined channels: $\phi$ is the angle inclined from the horizon. 
pressure difference produced in either a hydrophilic or hydrophobic system.

Combining E qs. $5-10$ yields the steady-state TCP velocity $\nu$ for either a hydrophilic or hydrophobic system in a uniform diameter channel with a round, slit-like, or square cross-section

$$
\begin{array}{r}
\nu=\frac{G d}{S \mu L}\left[\left(a-b T_{A}\right) \cos \theta_{A}-\left(a-b T_{R}\right) \cos \theta_{R}\right] \\
+\frac{\Delta P_{e} d^{2}}{S \mu L}+\frac{d^{2} \rho g \sin \phi}{S \mu} .
\end{array}
$$

U pon rearranging, we obtain an expression for the drop's velocity based on the difference in temperatures between the advancing and receding ends of a hydrophilic drop

$$
\nu=\frac{d G b \cos \theta_{R}}{L S \mu}\left(\Delta T-\Delta T_{\min }\right)+\frac{d^{2}}{S \mu L}\left(\Delta P_{e}+\rho g L \sin \phi\right)
$$

where

$$
\Delta \mathrm{T}=\mathrm{T}_{\mathrm{R}}-\mathrm{T}_{\mathrm{A}}
$$

and

$$
\Delta \mathrm{T}_{\text {min }}=\left(\mathrm{T}_{\mathrm{R}}-\mathrm{T}_{\mathrm{A}}\right)_{\min }=\left(\frac{\mathrm{a}}{\mathrm{b}}-\mathrm{T}_{\mathrm{A}}\right)\left[1-\frac{\cos \theta_{\mathrm{A}}}{\cos \theta_{\mathrm{R}}}\right]
$$

To obtain the form of Eq. 12 for hydrophobic systems, simply exchange the A (advancing) and R (receding) subscripts and add a minus sign immediately after the equal sign.

In addition to the temperature driving force in $\mathrm{E} \mathrm{q.} \mathrm{12,} \mathrm{there}$ are other contributions to fluid motion including a gravity term (body force), an applied pressure term, and most importantly, the contact angle hysteresis term found in $\Delta T_{\min } . \Delta T_{\min }$ is the minimum temperature difference needed to overcome contact angle hysteresis and initiate TCP in the absence of external pressures and gravity. Contact angle hysteresis is attributed to surface heterogeneity or contamination (Bartell and Cardwell, 1942; M ichaels and Dean, 1962; de Gennes, 1985; Brandon et al., 1997), microscopic surface roughness (Bartell and Shepard, 1953; Johnson, Jr. and D ettre, 1964; Bikerman, 1950; J in et al., 1997; Collet et al., 1997), and surface immobility (H iemenz, 1986; A damson, 1990). The hysteresis causes the advancing contact angle to increase above its static value and the receding contact angle to decrease below its static value (Figure 2 ). This hysteresis reduces the induced pressure difference; consequently, a minimum nonzero pressure difference must be attained before the drop will move (West, 1911; Y arnold, 1938; Schwartz et al., 1964).

The equation for the velocity of a liquid drop (Eq. 12) should be valid for a wide range of liquids and channel geometries. We have tested this theory by measuring TCP velocity in actual microfabricated devices for a few liquids. Those results are described next followed by a discussion of extensions to the theory.

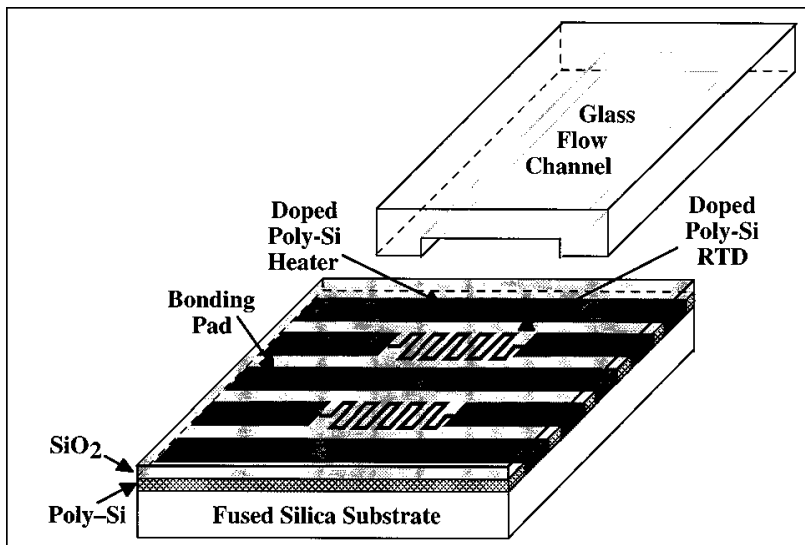

(a)

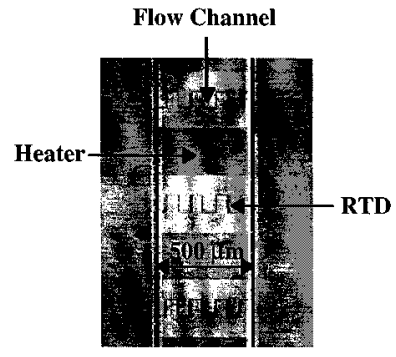

(b)

Figure 3. (a) Two-piece microfabricated flow device used for testing TCP; (b) optical photograph of heater elements and temperature sensors (RTDs) viewed through the channel region of a microfabricated TCP device.

The bottom portion of the device in (a), the heater substrate, consists of doped poly-silicon elements that are used as resistive heaters and resistive temperature detectors (RTDs). The device is completed by bonding a glass channel-cap above the heaters/sensors. The flow channel in (b) is $500 \mu \mathrm{m}$ wide while the heaters shown are $250 \mu \mathrm{m}$ wide, although $500 \mu \mathrm{m}$ wide resistive heaters were also tested.

\section{Materials and Methods \\ Device fabrication}

Flow Channel. The flow channels (top portion of Figure 3a) were etched into glass wafers ( $500 \mu \mathrm{m}$ thick, $10 \mathrm{~cm}$ diameter, Corning glass $\mathrm{N}_{0}$. 7740) using a $\mathrm{H} \mathrm{NO}_{3}: \mathrm{HF}$ [3:7] etching solution. The wafer level mask for the etchant consists of an evaporated Chrome/G old (600/3500 A) layer in combination with a hardbaked $(\sim 2 \mathrm{~h})$ photoresist layer $(\sim 3 \mu \mathrm{m})$. Channel depths of $\sim 20-50 \mu \mathrm{m}$ were obtained by varying the etch time from $\sim 4-10 \mathrm{~min}$.

H eater/Temperature-Sensor Chip. A $\sim 6,000 \AA$ fine grain polysilicon layer was deposited onto a fused silica wafer (500 $\mu \mathrm{m}$ thick and $10 \mathrm{~cm}$ diameter, GM A ssociates, I nc., 0 akland, CA ) by chemical vapor deposition (CV D) at $\sim 600^{\circ} \mathrm{C}$ (Figure $3 a)$. The heaters were patterned into the polysilicon layer (Figure $3 b$ ) by ion implantation of phosphorous (energy $=50$ $\mathrm{keV}$, dose $=10^{16} / \mathrm{cm}^{2}$ ). A $\sim 5,000 \AA$ low-temperature oxide (LTO) layer was deposited over the polysilicon using CV D at $\sim 400^{\circ} \mathrm{C}$. N ext, both the implant and LTO were subjected to 


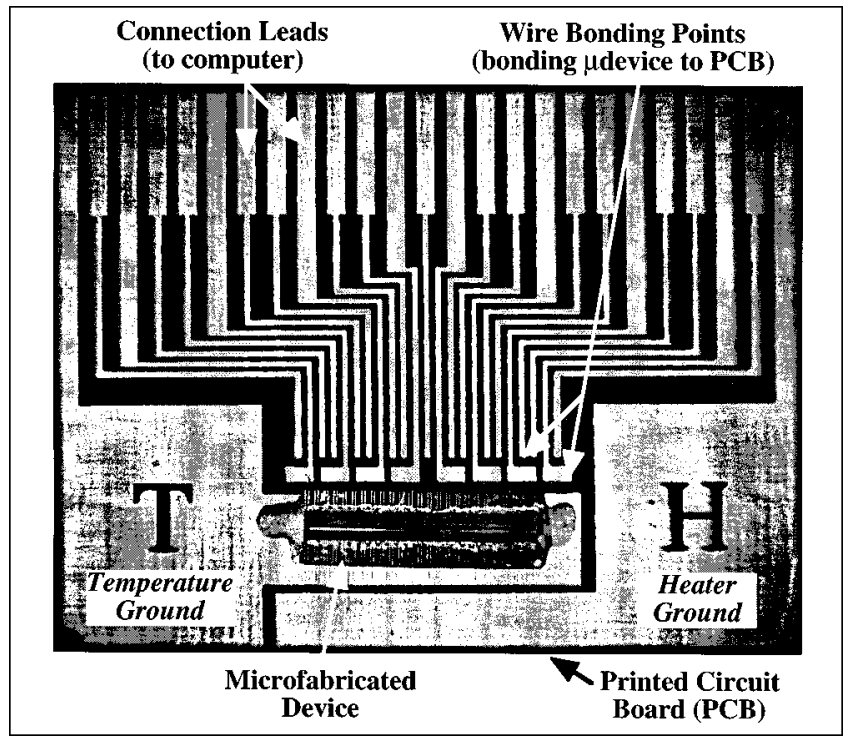

Figure 4. Wire bond connections between the microfabricated device and leads on a printed circuit board.

Individual heaters and RTD s on the device are interfaced to a computer through these lead connections. Note, the $\mathrm{H}$ and $\mathrm{T}$ etched into the circuit board are used to indicate the heater and temperature sensor grounding leads, respectively.

a rapid thermal anneal ( $\mathrm{RTA}$ ) step at $1,000^{\circ} \mathrm{C}$ for $30 \mathrm{~s}$ to activate the implant and anneal the LTO. Vias to the heater/RTD elements were wet etched through the LTO using buffered oxide etchant (BHF). Lastly, the exposed contact pads were metalized by evaporating a chrome/gold layer ( $600 \AA / 3,500 \AA$ ) into the openings and using a liftoff process to remove the unwanted metal.

Channel-to-H eater Chip Bonding. The glass flow channels were aligned over the heater/RTD elements on the heater chip (Figure 3) and bonded together using a UV curing adhesive (SK -9 Lens Bond; Sumers Laboratories, Fort Washington, PA). The adhesive was cured under a $365 \mathrm{~nm} \mathrm{U} \mathrm{V} \mathrm{lamp}$ for $\sim 12 \mathrm{~h}$

\section{Testing setup}

To control the microfabricated devices with a computer, the completed devices were glued with epoxy and then wire bonded to a printed circuit board (Figure 4). The deviceprinted circuit board combination was then interfaced to a computer-controlled data acquisition system through a card edge connector. A LabV iew based data acquisition and control system enabled us to monitor and control several RTDs simultaneously. Transient temperature data in the form of RTD voltages were collected at a rate of $1,250 \mathrm{~Hz} /$ channel using a $\mathrm{PCl}$ based sixteen bit data acquisition board from National Instruments ( $\mathrm{PCl}$ MIO 16XL). The simultaneous monitoring and control of several different heaters was also achieved using the same LabView system and a solid-state relay board connected to the device heaters.

\section{M easurements}

Velocity. D rop location within the microfabricated channels was achieved visually using a color CCD camera mounted to a co-axially illuminated stereoscope (Olympus SZH 10). TCP velocities were obtained by applying a voltage to a preselected heater under the rear meniscus of the drop and observing the resulting movement. The motion of a drop undergoing TCP was recorded on video and the images were processed to determine TCP pumping velocity by monitoring the distances covered by the drop as a fixed number of video frames had elapsed (30 frames/s).

Temperature. In order to calculate RTD resistances from the voltage readings, a known resistor $\left(R_{\text {divider }}\right.$ ) (typically $\sim 10$ $\mathrm{k} \Omega$ ) was placed in series before each RTD to form a voltage divider circuit. A constant voltage $\left(\mathrm{V}_{\mathrm{T}}\right)$ was applied (typically $\sim 5 \mathrm{~V})$ and the resistance of the temperature sensor $\left(R_{R T D}\right)$ was calculated by measuring the voltage drop across the sensor $\left(\mathrm{V}_{\text {divider }}\right)$,

$$
R_{R T D}=\left(\frac{V_{\text {divider }}}{V_{T}-V_{\text {divider }}}\right) R_{\text {divider }} \text {. }
$$

Calibration data were obtained by controlling the device temperatures with a Peltier device and measuring the temperature at the surface of the heater chip with a fine tip thermocouple. Typically, 3-4 calibration data points were taken from $\sim 10^{\circ} \mathrm{C}-80^{\circ} \mathrm{C}$. The data, in the form of RTD resistance vs. temperature, were then correlated with a linear least-squares fit.

D uring the experiments, a computer-controlled data acquisition system was used to record transient temperature readings at a rate of 75 points/s for each RTD. To smooth electrical noise, the temperature readings were taken as averages of 25 data points, generating $\sim 3$ temperature readings per second. Temperature differences (between the drop ends) were determined from the difference in temperatures between the RTDs located beneath the drop's two menisci. Lastly, to prevent stray heater voltages from influencing the RTD's temperature signal, heaters were pulsed rather than continuously run; RTD measurements were taken between pulses.

Contact Angle. The microfabricated channels were connected, at one end, to a low-pressure compressed air source and submerged in liquid (F igure 5). A dvancing contact angles were calculated from Eq. 4 by measuring the pressure needed to advance a meniscus in our flow channels. Receding contact angles were determined from measuring the pressure needed to retract the meniscus. The equation used to calculate the contact angles is based upon a rearrangement of $\mathrm{Eq}$. 4

$$
\theta_{\mathrm{A}, \mathrm{R}}=\cos ^{-1}\left(\frac{\mathrm{P}_{\mathrm{C}} \mathrm{d}}{\mathrm{G} \sigma}\right)=\cos ^{-1}\left[\frac{\mathrm{d}}{\mathrm{G} \sigma}\left(\mathrm{P}_{\text {applied }}-\rho \mathrm{gh}\right)\right] \text {. }
$$

\section{Experimental Results \\ Heater performance}

Since TCP is dependent upon temperature control for drop pumping, microfabricated TCP devices must be capable of 


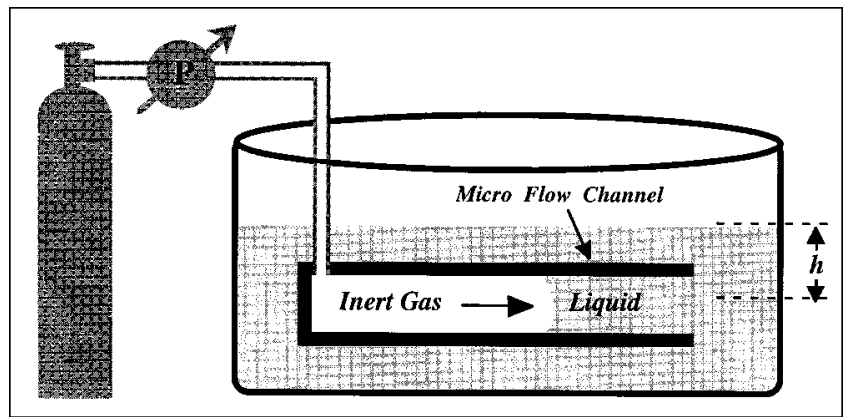

Figure 5. Pressure system used to indirectly measure the advancing and receding contact angle produced in the microfabricated TCP devices.

localized temperature control in liquid drops. Figure 6 shows transient temperature responses at several locations throughout a mineral oil drop that was heated at one end with $15 \mathrm{~V}$. N otice that, while the temperature of the heated end (R TD s-1 and 2) increased by $\sim 35^{\circ} \mathrm{C}$, the temperature at the opposite end of the drop (RTD-6) increased by only $\sim 5^{\circ} \mathrm{C}$. Consequently, the temperature increases remained essentially localized to the heated side of the drop, thus allowing for higher values of $\Delta T$ (the driving force for TCP) than if the entire drop were extensively heated throughout its length.

The temperatures in Figure 6 increased continually for more than $30 \mathrm{~s}$ while the heater was active. The $\Delta T$ driving force for TCP, however, quickly reached a constant value of $\sim 31^{\circ} \mathrm{C}$ in $\sim 3 \mathrm{~s}$, as shown in Figure 7. The extremely low

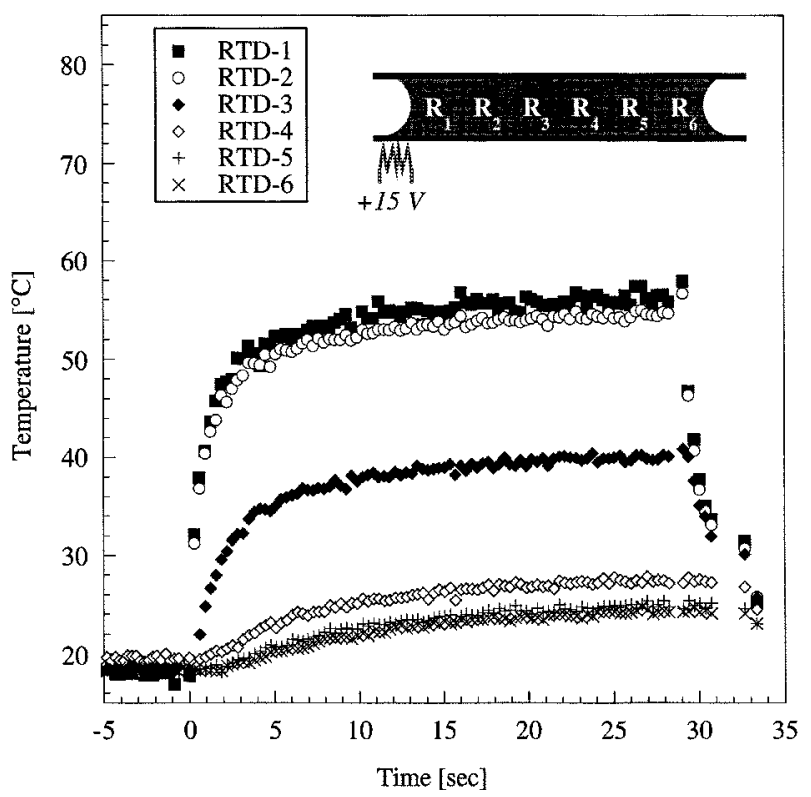

Figure 6. Transient temperature distributions produced in a $\sim 0.5-\mathrm{cm}$-long drop of mineral oil after heating one end of the drop with $15 \mathrm{~V}$.

Although the temperature at the heating interface rises rapidly and significantly, the temperature at the opposite end of the drop shows only a slight increase.

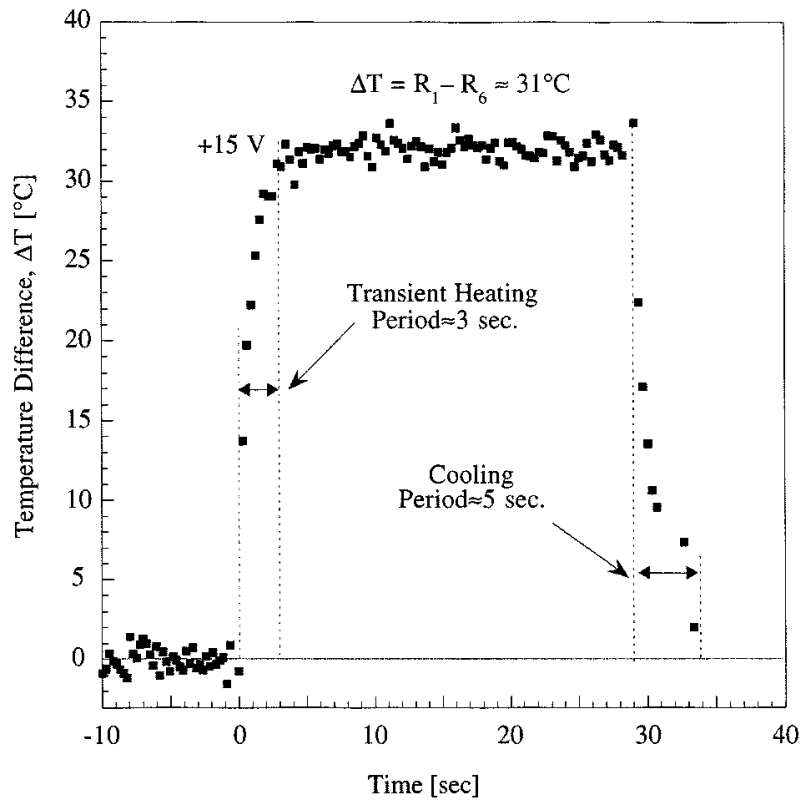

Figure 7. Transient temperature differences $\Delta T$ (given by the difference measured between RTD-1 and RTD-6) produced by the system shown in Figure 6.

Although the specific temperatures throughout the drop continuously change, the $\Delta T$ driving force for $T C P$ reaches a constant value of $\sim 31^{\circ} \mathrm{C}$ in about $3 \mathrm{~s}$. The cooling period is also short allowing the system to return to a near-zero $\Delta \mathrm{T}$ in about $5 \mathrm{~s}$.

masses of the liquids contained within microfabricated devices allows for such rapid thermal responsiveness. This responsiveness is also evident during liquid cooling. In Figure 7 , the system cools to a near-zero $\Delta \mathrm{T}$ in $\sim 5 \mathrm{~S}$.

The magnitude of $\Delta T$ can be set by controlling the voltage level applied to each resistive heating element as shown in Figure 8. As the heater voltage is cycled from 5 to $18 \mathrm{~V}, \Delta \mathrm{T}$ cycles between $\sim 10^{\circ} \mathrm{C}$ to $\sim 70^{\circ} \mathrm{C}$. Although the maximum temperature differences attained during meniscus heating is dependent upon the applied voltage, in practice, it can be limited by the stability of the liquid. F or instance, consider an analysis system that uses a biological enzyme that is inactive above $65^{\circ} \mathrm{C}$. If the system is initially at room temperature $\left(\sim 25^{\circ} \mathrm{C}\right.$ ), then $\mathrm{TCP}$ velocity is biologically limited to a $\Delta \mathrm{T} \approx$ $30^{\circ} \mathrm{C}$ driving force. By precooling the drop, however, $\Delta \mathrm{T}$ can be increased without raising the temperature at the heated meniscus. As an example, the system in Figure 8 was precooled to $\sim 10-15^{\circ} \mathrm{C}$ using a thermoelectric cooler (Peltier device) beneath the flow channel. By precooling to less than $5^{\circ} \mathrm{C}$, we were able to increase $\Delta \mathrm{T}$ by nearly $20^{\circ} \mathrm{C}$ without increasing the maximum temperatures obtained within the drop.

\section{Temperature-induced $v$ elocities}

TCP experiments were performed in microfabricated flow channels that roughly resemble a rectangular slit (width to height ratios ranging from $10-25$ ). Although mineral oil, 


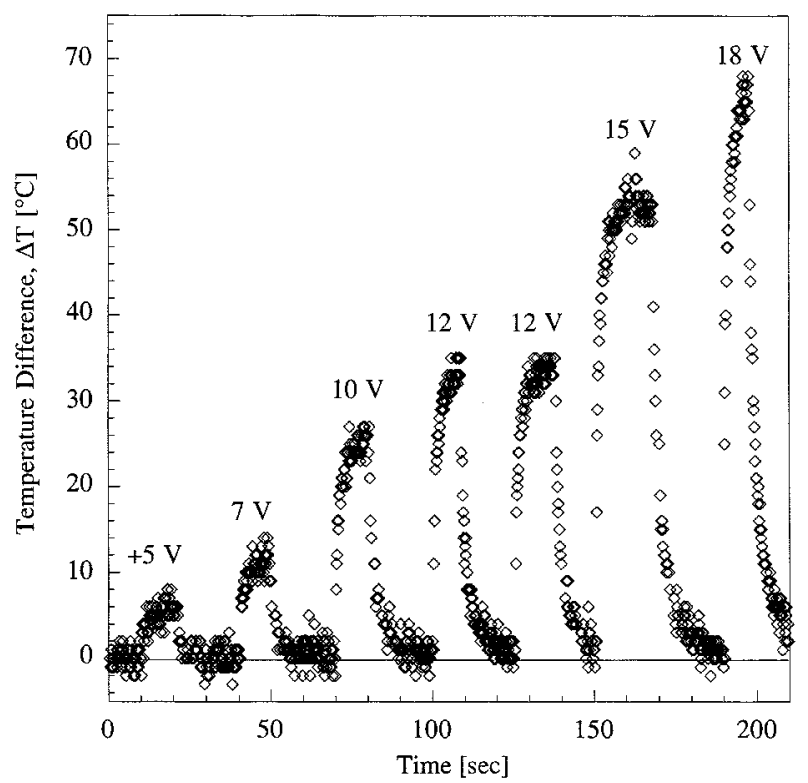

Figure 8. Effect of applied voltage on the resulting transient temperature difference $\Delta T$ in a $\sim 0.5-\mathrm{cm}$ long drop of mineral oil heated at one end.

$\Delta \mathrm{T}$ rapidly returns to an approximately zero temperature difference after each heating cycle. The temperature at any location can be controlled to less than a degree using a feedback control algorithm (Burns et al., 1996).

toluene, and water were all used in TCP experiments, mineral oil was used most often due to its relatively high boiling point $\left(>350^{\circ} \mathrm{C}\right.$ ) (see Table 1). Furthermore, a single drop of mineral oil can be reused for successive experiments over several days without evaporating.

TCP experiments were performed on drops of liquid ranging in volume from $\sim 10-100 \mathrm{~nL}$ (Figure 9). The procedures used for measuring drop velocities and induced temperature differences are described in the $M$ aterials and $M$ ethods section of this article. $V$ oltages ranging from $15-25 \mathrm{~V}$ were applied to a single heater located beneath one end of the drop. The resulting temperature differences, which ranged from $16-70^{\circ} \mathrm{C}$, induced drop velocities of up to $\sim 70 \mu \mathrm{m} / \mathrm{s}$ (see Figure 10). A s predicted by Eq. 12, these experimentally ob-

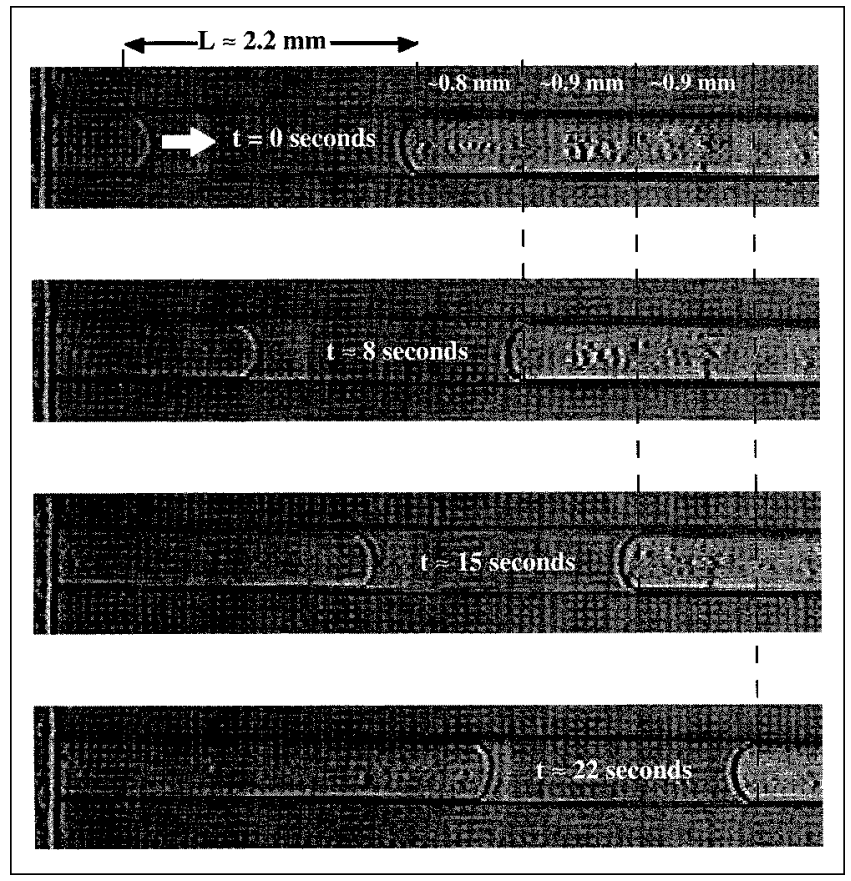

Figure 9. Video sequence of a $\sim 30-\mathrm{nL}$ drop of mineral oil undergoing TCP in a microfabricated device.

Drop motion occurred after the application of $20 \mathrm{~V}$ to the heater at the left end of the drop; an average drop velocity on the order of $100 \mu \mathrm{m} / \mathrm{s}$ was obtained.

served drop velocities increased linearly with increasing $\Delta T$. Their intersection with the $\mathrm{x}$-axis at $\sim 19^{\circ} \mathrm{C}$ corresponds to $\Delta \mathrm{T}_{\min }$ in $\mathrm{Eq}$. 12. This intersection point represents the minimum temperature difference needed to overcome contact angle hysteresis and initiate TCP.

A lthough the velocities for mineral oil appear low from a macroscopic viewpoint, such velocities are often sufficient for the microdistances associated with microfabricated devices. For instance, in our chemical analysis devices, the distance between the reaction and separation systems is typically on the order of a few millimeters. A drop moving at $70 \mu \mathrm{m} / \mathrm{s}$ will move over $4 \mathrm{~mm}$ in one minute. This time period is short

Table 1. TCP Parameters of Several Common Liquids at $22^{\circ} \mathrm{C}^{*}$

\begin{tabular}{llcccccc}
\hline Liquid & $\begin{array}{c}\mu_{0} \\
\text { (poise) }\end{array}$ & $\begin{array}{c}\rho_{0} \\
\left(\mathrm{~g} / \mathrm{cm}^{3}\right)\end{array}$ & $\begin{array}{c}\mathrm{T}_{\mathrm{b}} \\
\left({ }^{\circ} \mathrm{C}\right)\end{array}$ & $\begin{array}{c}\mathrm{a} \\
(\text { dyn/cm })\end{array}$ & $\begin{array}{c}\mathrm{b} \\
(\mathrm{dyn} / \mathrm{cm} / \mathrm{C})\end{array}$ & $\begin{array}{c}\mathrm{a} / \mathrm{b} \\
\left({ }^{\circ} \mathrm{C}\right)\end{array}$ & $\begin{array}{c}\mathrm{b} / \mu_{\mathrm{o}} \\
\left(\mathrm{cm} / \mathrm{s} /{ }^{2} \mathrm{C}\right)\end{array}$ \\
\hline A cetone & 0.00311 & $1.3588^{20^{\circ} \mathrm{C}}$ & 57 & 26.26 & 0.112 & 234.5 & 36.0 \\
$\mathrm{H}_{2} \mathrm{O}_{2}$ & 0.0125 & 1.4639 & 152 & 78.97 & 0.1549 & 509.8 & 12.4 \\
M ercury & 0.01552 & 13.54 & 357 & 490.6 & 0.2049 & 2394 & 13.2 \\
M ineral oil & $0.26^{\S}$ & 0.838 & $>350$ & $40.71^{* *}$ & $0.221^{\dagger}$ & 184.2 & 0.85 \\
Oleic acid & 0.256 & 0.891 & 194 & $34.19^{\ddagger}$ & 0.0694 & 492.7 & 0.3 \\
2-Propanol & 0.02348 & $0.7855^{20^{\circ} \mathrm{C}}$ & 82 & 22.90 & 0.0789 & 290.2 & 3.4 \\
Toluene & 0.005763 & 0.866 & 111 & 30.9 & 0.1189 & 259.9 & 20.6 \\
Water & 0.009548 & 0.997 & 100 & 75.83 & 0.1477 & 513.4 & 15.5 \\
\hline
\end{tabular}

*Lange (1992).

**Surface tension constant $\mathrm{b}$ of mineral oil purchased from A Idrich Chemical Co. (Cat. No. 16, 140-3) and measured by SensaD yne Instruments of M esa, AZ.

t'Surface tension constant a calculated using measured temperature coefficient $\mathrm{b}^{\mathrm{ii}}$ and surface tension given by $\mathrm{R}$ ose and $\mathrm{H}$ eins $(1962)$ at $22^{\circ} \mathrm{C}$.

${ }^{\ddagger}$ Surface tension constant a calculated using literature value for temperature coefficient $b$ and surface tension given by $R$ ose and $H$ eins $(1962)$ at $22^{\circ} \mathrm{C}$.

${ }^{\S}$ Shear viscosity measured by a cone and plate viscometer. 


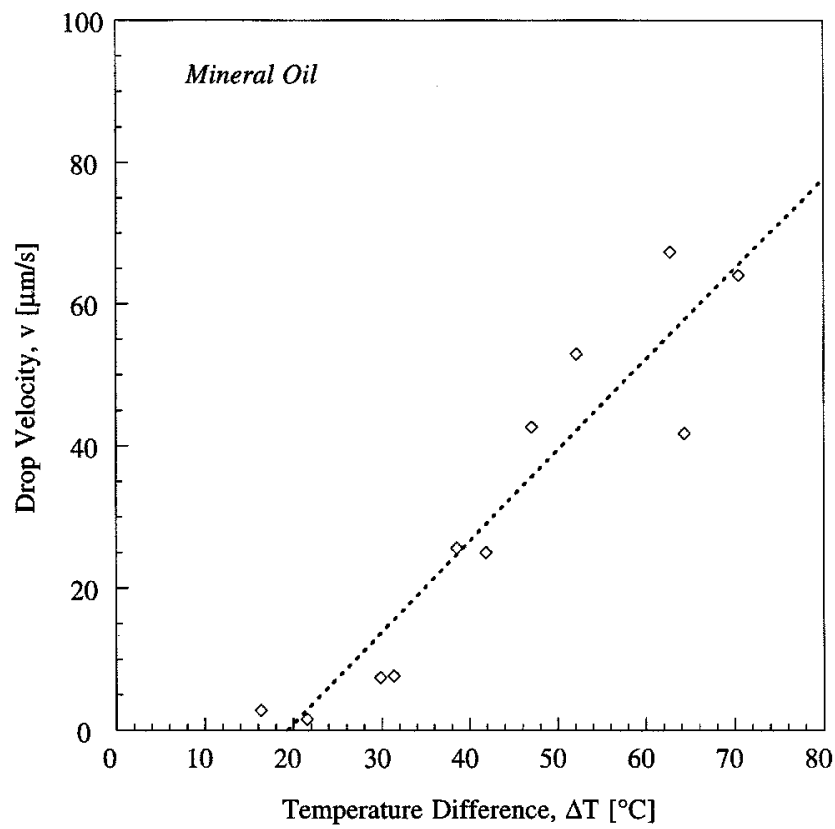

Figure 10. Experimentally measured TCP velocities for mineral oil in a microfabricated device.

The induced temperature differences, which ranged from $\sim 15-70^{\circ} \mathrm{C}$, produced velocities up to $\sim 70 \mu \mathrm{m} / \mathrm{s}$. The flow channel used was $32 \mu \mathrm{m}$ high and $\sim 500 \mu \mathrm{m}$ wide.

relative to typical reaction and separation times associated with many chemical analysis systems (on the order of tens of minutes).

Although sufficient for microdevices, the TCP velocities produced with mineral oil are low relative to those of other liquids such as toluene and water. The relatively low velocities for mineral oil are, in part, a consequence of its low $\mathrm{b} / \mu$ ratio (see Table 1 ). The $\mathrm{b} / \mu$ value for toluene $\left(21 \mathrm{~cm} / \mathrm{s} /{ }^{\rho} \mathrm{C}\right.$ ) is about 25 times greater than that for mineral oil $(0.85$ $\mathrm{cm} / \mathrm{s} /{ }^{\circ} \mathrm{C}$ ). Consequently, toluene should exhibit significantly larger TCP velocities than mineral oil at similar temperature differences. Figure 11 shows TCP results for toluene in a microfabricated flow device that is similar to the device used for the mineral oil experiments. As expected from the theory, the data for toluene exhibit both a linearly increasing velocity trend and a nonzero minimum temperature difference of $\sim 11^{\circ} \mathrm{C}$. However, drop velocities on the order of several hundred microns per second were obtained for toluene while mineral oil produced velocities on the order of tens of microns per second. Consequently, the travel time for moving a drop $4 \mathrm{~mm}$ would be reduced from one minute for mineral oil to $\sim 10 \mathrm{~s}$ for toluene. Similar improvements in the magnitude of velocity were seen with water.

\section{Comparing experiments with theory}

$U$ sing the procedure outlined in the $M$ aterials and $M$ ethods section, we measured advancing and receding contact angles of $49.8 \pm 4.1^{\circ}$ and $47.6 \pm 4.4^{\circ}$, respectively, for a drop of mineral oil moving in our microfabricated devices. Based upon the parameters given in Table 1 and the contact angles experimentally determined for this system, Eq. 14 predicts that $\Delta \mathrm{T}_{\min } \approx 7^{\circ} \mathrm{C}$; however, a value of $\sim 19^{\circ} \mathrm{C}$ was found experimentally. This difference may be attributed to uncertainty in the pressure measurements used to determine $\theta_{\mathrm{A}}$ and $\theta_{R}$, or to slightly varying channel conditions at the time of the measurement. A difference as slight as having $\theta_{\mathrm{A}} \approx 50$ $\rightarrow 52^{\circ}$ and $\theta_{\mathrm{R}} \approx 48 \rightarrow 47^{\circ}$ would shift the predicted $\Delta \mathrm{T}_{\text {min }}$ from $7^{\circ} \mathrm{C}$ to $18^{\circ} \mathrm{C}$. Such deviations are within the range of experimental uncertainty for the contact angles.

The accuracy of the experimental data from the microdevices was confirmed by experiments in which a velocity was created by an external pressure source rather than by temperature differences. These pressure-driven data are shown in Figure 12 and are used to determine the shape constant $(S \approx 37)$ particular to the channel cross-section in the microdevices. With this device specific shape constant, theoretical TCP velocities were calculated and compared to the experimental values (Figure 12). Note that when plotted on equivalent axes, both the TCP and pressure generated velocity data agree with each other indicating that the pressures calculated from surface-tension variations are correct. Furthermore, when theoretical predictions are added based on the calculated shape factor $(S \approx 37)$ and contact angles, both data sets lie within the range of uncertainty in the theory. The wide uncertainty range for the theory is due predominantly to uncertainty in obtaining accurate contact angles.

A lthough unlikely, it is possible that an error in the experimental data could result from an end effect associated with the flow of discrete drops. Equation 12, the model for TCP velocity, was derived from the Poiseuille flow solution for a continuously flowing liquid (Bird et al., 1960). To test whether

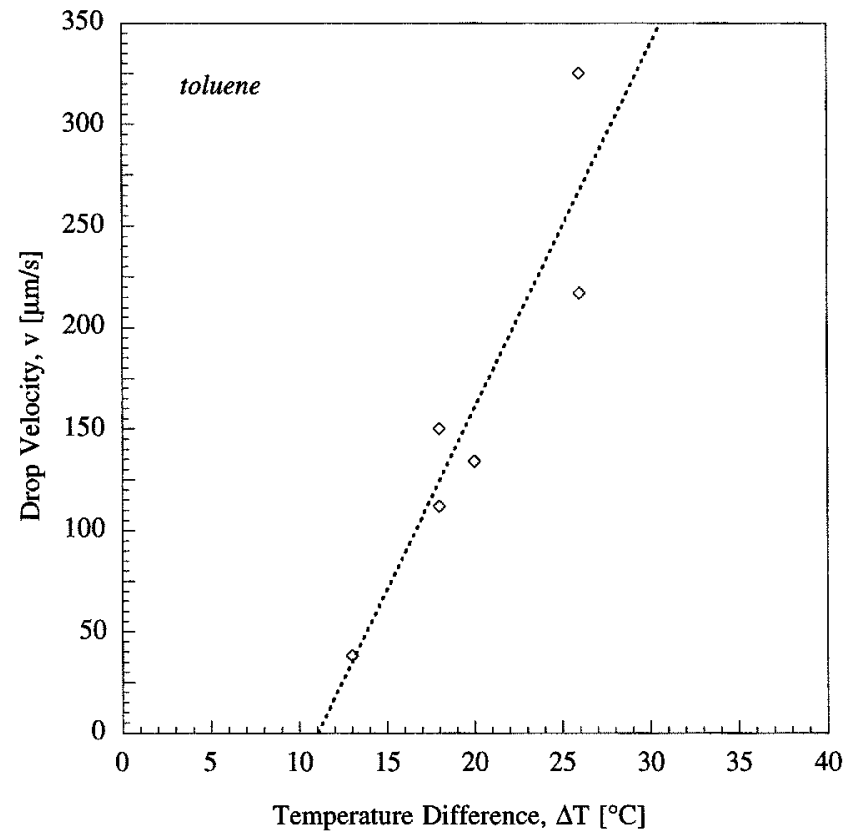

Figure 11. Experimental TCP velocities measured for toluene in a microfabricated device.

The relatively low induced temperature differences, less than $30^{\circ} \mathrm{C}$, produced velocities of over $300 \mu \mathrm{m} / \mathrm{s}$. The flow channel used was $32 \mu \mathrm{m}$ high and $500 \mu \mathrm{m}$ wide. 


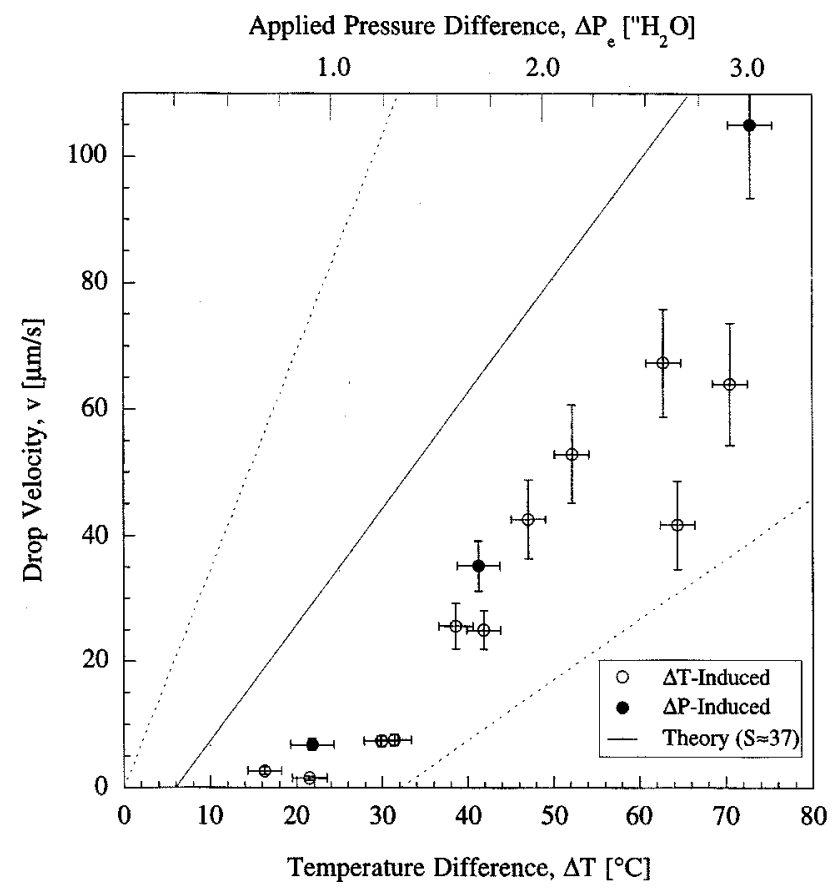

Figure 12. Experimental velocities (Figure 10) vs. theoretical predictions based on Eq. 12 using measured contact angles of $\theta_{A}=49.8 \pm 4.1^{\circ}$ and $\theta_{R}=\mathbf{4 7 . 6} \pm 4.4^{\circ}$.

The theory agrees with TCP data for microdevices $(O)$ within the range of experimental uncertainty (---). The velocity results from an externally applied pressure (O) agree with experimental TCP results when plotted on equivalent scales. The pressure scale was chosen so that the pressure data align with their corresponding temperature values; consequently, the theory line applies to both the $\Delta \mathrm{P}_{\mathrm{e}}$ and $\Delta \mathrm{T}$ axes.

end effects are important in this situation, we performed movement experiments on drops of various lengths in rectangular glass tubes (Wale A pparatus, H ellertown, PA). The dimensions of the channels in these capillary tubes $(50 \mu \mathrm{m} \times 500$ $\mu \mathrm{m})$ were similar to those in our devices $(32 \mu \mathrm{m} \times 500 \mu \mathrm{m})$. $\mathrm{U}$ sing an external pressure source, different velocities were induced in drops of lengths $2.5,12$ and $21 \mathrm{~mm}$. The results, shown in Figure 13, were plotted in the form of drop velocity divided by $d / L$ vs. applied pressure. The normalized velocity equation that this manipulation is based on

$$
\frac{\nu}{\mathrm{d} / \mathrm{L}}=\left(\frac{\mathrm{d}}{\mathrm{S} \mu}\right) \Delta \mathrm{P}_{\mathrm{e}}-\frac{\Delta \mathrm{T}_{\min } \mathrm{G} \mathrm{b} \cos \theta_{\mathrm{R}}}{\mathrm{S} \mu_{\mathrm{o}}}
$$

is obtained by dividing $\mathrm{Eq} .12$ by $\mathrm{d} / \mathrm{L}(\Delta \mathrm{T}=\phi=0)$. Note that, in Figure 13, the data for all three different drop lengths converge to a single straight line as predicted by Eq. 17.

The experimental data agree with theoretical predictions for a rectangular channel (where $\mathrm{S} \approx 12$ in $\mathrm{Eq} .17$ ) within the range of uncertainty from the experimental parameters; adjusting $S$ (the shape is not a perfect rectangle) would have produced an even better agreement. This agreement suggests that the theory representation of TCP presented is valid for discrete drop systems. These results confirm those reported by Rose and $\mathrm{H}$ eins (1962), whose discrete drops with $\mathrm{L} / \mathrm{d}>$ 100 exhibited Poiseuille flow behavior. Note that, unlike the actual device whose shape constant was measured $(S \approx 37)$ because of the trapezoidal shape of its flow channel, a reported value of $S \approx 12$ (Green, 1984) was used in predictions for the more common rectangular capillary shape. This difference in shape constant between rectangular and trapezoidal channel cross-sections is consistent with observations reported elsewhere in the literature (Harley and Bau, 1989; U rbanek et al., 1993; Richter et al., 1997). Note that, although it is possible to microfabricate channels with vertical side walls (rectangular) by anisotropically etching $\langle 100\rangle$ silicon, the channel cap would be opaque making visual observation of the liquid within it quite difficult.

$M$ any other liquids could be pumped by TCP other than the three reported here; Table 1 lists several common liquids with their physical constants that are relevant to TCP. Some liquids appear more suited than others for TCP by nature of their physical properties. Properties that are advantageous are: low viscosity, high boiling point, high surface tension temperature coefficient, and low hysteresis of contact angles. As discussed in the previous section, liquids with low $\mathrm{b} / \mu$ values - such as mineral oil-are likely to yield much lower

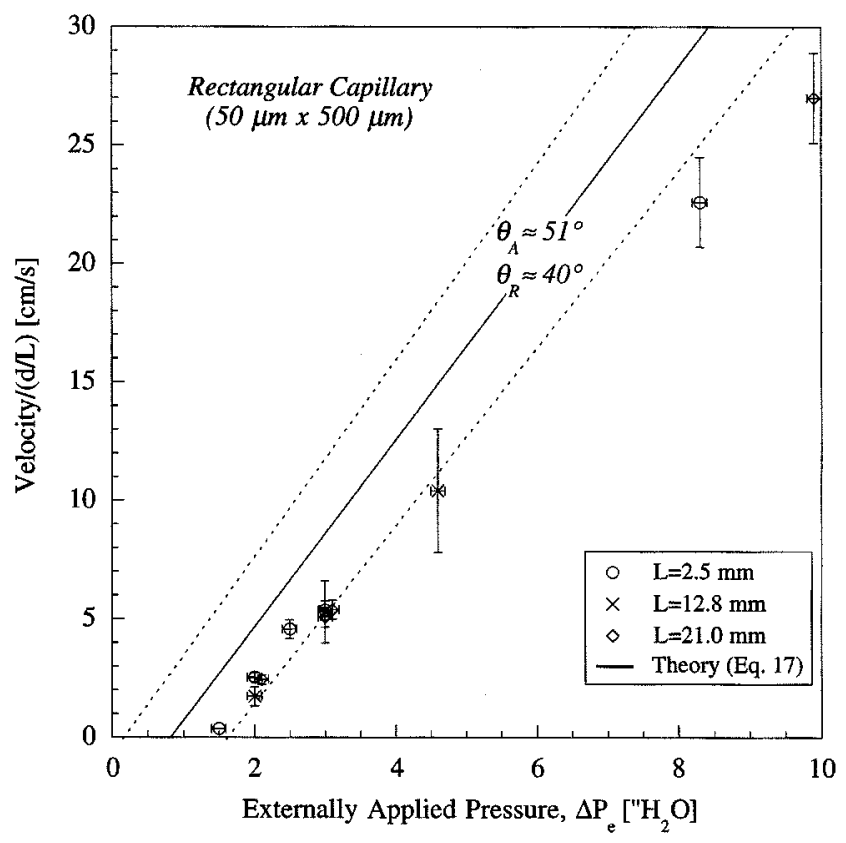

Figure 13. Velocity results for drops of mineral oil of various lengths in a rectangular glass capil-

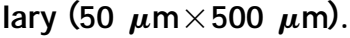

The velocities were induced using an externally applied pressure source. The experimental and theoretical ( - ) results for this ideal rectangular channel system agree within the range of experimental uncertainty (-- ). This result suggests that the TCP theory is valid for discrete drops of various lengths. $A$ shape constant of $S \approx 12$ for a rectangular channel and measured contact angles $\theta_{\mathrm{A}}=$ $50.6 \pm 3.4^{\circ}$ and $\theta_{R}=39.6 \pm 4.8^{\circ}$ were used to plot the theory lines; using an adjusted value for $S$ would have given even better agreement with the theory. 
velocities than liquids with higher $b / \mu$ values-such as toluene. Conversely, although acetone has a very high $\mathrm{b} / \mu$ value $(36 \mathrm{~cm} / \mathrm{s} / \mathrm{C})$, its volatile nature and low boiling temperature $\left(57^{\circ} \mathrm{C}\right)$ make it an unlikely candidate for TCP. As a final example, mercury is severely limited by its extremely high $\mathrm{a} / \mathrm{b}\left(2,394^{\circ} \mathrm{C}\right)$ value (see Eq. 14). If any significant level of contact angle hysteresis exists in a mercury system, its high $\mathrm{a} / \mathrm{b}$ value would require a $\Delta \mathrm{T}_{\min }$ that would likely exceed the practical limits of microfabricated systems.

\section{Theoretical Extensions}

The theoretical framework developed at the beginning of this article served as both an introduction and explanation of TCP. This section is intended to introduce extensions to TCP that may be useful for both understanding and enhancing its effect. First, the effects of varying liquid and channel parameters on the temperature dependence of TCP velocity will be examined. N ext, the effects of contact angle hysteresis on TCP will be explored. A nd lastly, mechanisms for countering contact angle hysteresis will be introduced. U nless otherwise stated, the following analyses will assume hydrophilic channels; the analysis procedures are the same for hydrophobic channels except for some minor sign and subscript changes in the governing equations.

\section{System parameters affecting velocity}

Equation 12 is the complete equation for TCP in hydrophilic systems; however, when the channel is horizontal, the gravity term becomes zero. For further simplicity in evaluating the effect of parameters associated with the temperature term in Eq. 12, we will assume that both contact angle hysteresis and external pressures are absent. In this case, $\nu$ is given by

$$
\nu=\left(\frac{\mathrm{dG} b \cos \theta}{\mathrm{LS} \mu_{\mathrm{o}}}\right) \Delta \mathrm{T}
$$

The magnitude of this velocity is governed by the following system properties: $\mathrm{b} / \mu_{\mathrm{o}}$ (liquid properties), $\theta_{\mathrm{A}}=\theta_{\mathrm{R}}=\theta$ (contact angle), L/d (drop dimensions), and G/S (channel shape).

The liquid properties affect the magnitude of the velocity through the parameter $\mathrm{b} / \mu_{0}$. Figure 14 contains calculated velocities for five different $\mathrm{b} / \mu_{0}$ values. Notice that $\mathrm{as} b / \mu_{0}$ increases, the velocity increases. Fortunately, even the lowest velocities shown on Figure 14 should be sufficient for pumping over the distances of several millimeters or less, as frequently found in microfabricated devices.

The magnitude of TCP velocity is also affected by the contact angle. As the contact angle increases in a hydrophilic channel, the magnitude of the TCP velocity decreases, becoming zero at $\theta=90^{\circ}$. For systems that yield low contact angles, the effect of a nonzero contact angle is quite small. For instance, the decrease in velocity as the contact angle increases from $0^{\circ}$ to $20^{\circ}$ is only $6 \%$; not until $\theta=60^{\circ}$ does the velocity drop to half its maximum value. Note that in hy-

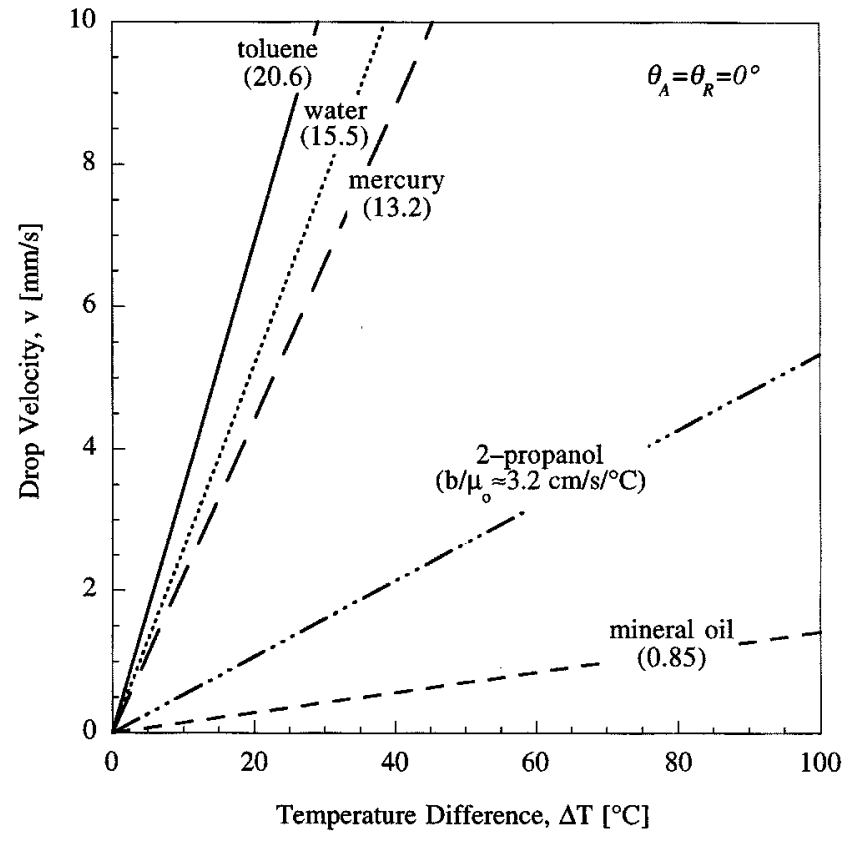

Figure 14. Dependence of TCP velocity on the difference in temperatures between the ends of a hydrophilic drop in the absence of contact angle hysteresis.

The magnitude of velocity highly depends on the ratio of the temperature coefficient of surface tension to the viscosity of the liquid $\mathrm{b} / \mu_{0}$. In this slit channel system, both contact angles $\left(\theta_{A}, \theta_{R}\right)$ are zero, the ratio of drop length to drop diameter $(\mathrm{L} / \mathrm{d})$ is 100 , and the initial drop temperature $\left(\mathrm{T}_{0}\right)$ is $22^{\circ} \mathrm{C}$.

drophobic systems where the advancing interface is heated, the effect is exactly the opposite; TCP velocity increases from zero at $\theta=90^{\circ}$ to its maximum at $\theta=180^{\circ}$.

In addition to being influenced by both the liquid and solid-liquid interactions, TCP velocity is also dependent upon the geometry of the drop through the parameters $L / d$ and $\mathrm{G} / \mathrm{S}$. Since the channel diameter is fixed, $\mathrm{L} / \mathrm{d}$ can be controlled by altering the volume of a sample to make the drop longer or shorter. Figure 15 shows that, for a given temperature difference, TCP velocities decrease with increasing drop length-to-height ratios. This result is expected since longer drops provide more resistance to flow with no increase in driving force (pressure drop). Channel geometry ( $G / S$ ) has a much less pronounced effect on the velocity, altering it by only $\sim 20-30 \%$ for a given temperature difference (Figure 16). Note that slit geometries yield the highest TCP velocity for a given set of conditions while providing a much larger drop volume per unit length than either square or circular channels of the same height. Consequently, the volumetric flow rate in a slit system can be orders of magnitude higher than the other two channel geometries under the same temperature differences.

\section{Contact angle hysteresis}

Minimum Temperature Differences. Equation 14 reveals that the contact angle hysteresis parameter $\left(1-\cos \theta_{A} / \cos \theta_{R}\right)$ 


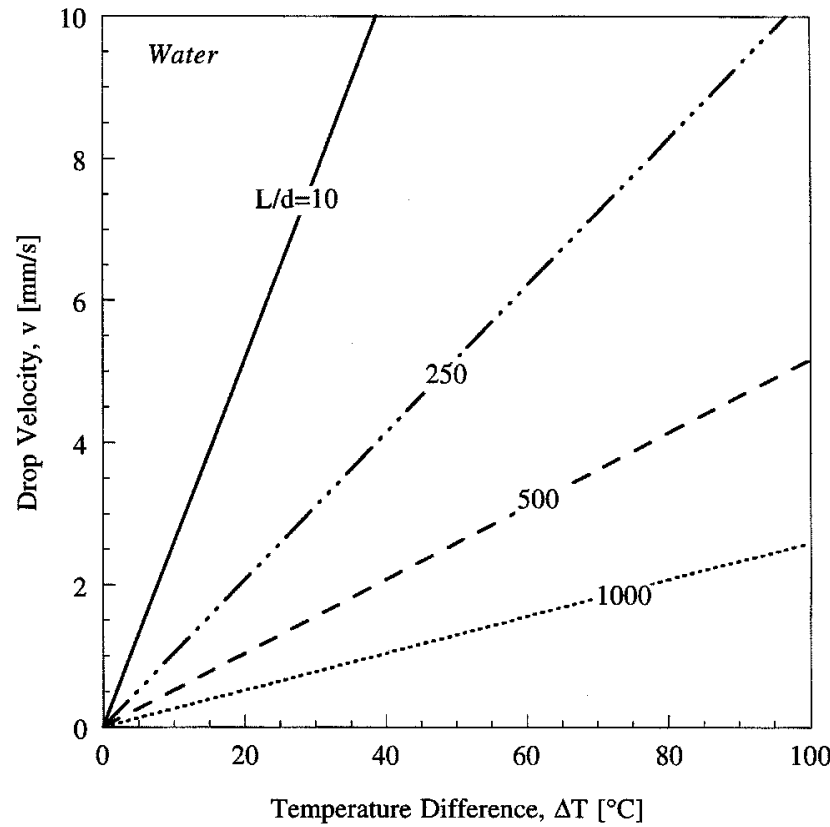

Figure 15. TCP velocity for water at various drop length-to-height ratios $L / d$ when contact angle hysteresis is absent.

In this example, the contact angle is zero and the initial drop temperature is $22^{\circ} \mathrm{C}$.

is, in essence, a measure of the relative effect of contact angle hysteresis on TCP. A lthough this hysteresis parameter is mathematically bound between zero and one, its bounds in practice are much smaller. The closer this hysteresis parameter is to zero, the lower the minimum temperature difference needed to overcome contact angle hysteresis. R ealistically, the maximum temperature that can be used in any system is $T_{b}-$ $T_{f}$, the difference between the liquid's boiling and freezing point temperatures.

For a given value of $\left(1-\cos \theta_{A} / \cos \theta_{R}\right)$, the value of $\Delta T_{\min }$ is affected by two parameters: the ratio of surface tension constants $a / b$ and the initial liquid temperature $T_{0}\left(T_{0}=T_{A}\right.$ in a hydrophilic system). As a/b increases, the minimum temperature difference needed increases as shown in Figure 17; since $a / b$ is defined by the liquid being pumped, certain liquids may require unacceptably high values of $\Delta \mathrm{T}_{\min }$. A Iternatively, the liquid temperature $T_{0}$ can be reduced to maximize the temperature difference $T_{b}-T_{0}$ (F igure 18). In practice, $T_{0}$ should be kept as low as possible to maximize $T_{R}-T_{A}$. Temperatures near the freezing point of some liquids may even be reached by using Peltier devices to cool the bulk of the drop while heating one of the interfaces.

Velocity and Temperature Dependence. Dynamic contact angles exhibit a dependence on interface velocity (D ussan, 1979; N gan and D ussan, 1982; A blett, 1923; Y arnold and $\mathrm{M} \mathrm{a-}$ son, 1948; R ose and Heins, 1962; Elliot and R iddiford, 1962; G utoff and Kendrick, 1982; J in et al., 1997); advancing angles increase with interfacial velocity while receding contact angles tend to decrease (Shikhmurzaev, 1996; Elliot and R iddiford, 1967; R ose and Heins, 1962). To study this effect on TCP, Nujol and oleic acid were chosen because velocity dependent dynamic contact angle data exist for them in the literature (Rose and $\mathrm{H}$ eins, 1962). A fit of the literature data yielded the following expressions relating contact angle and

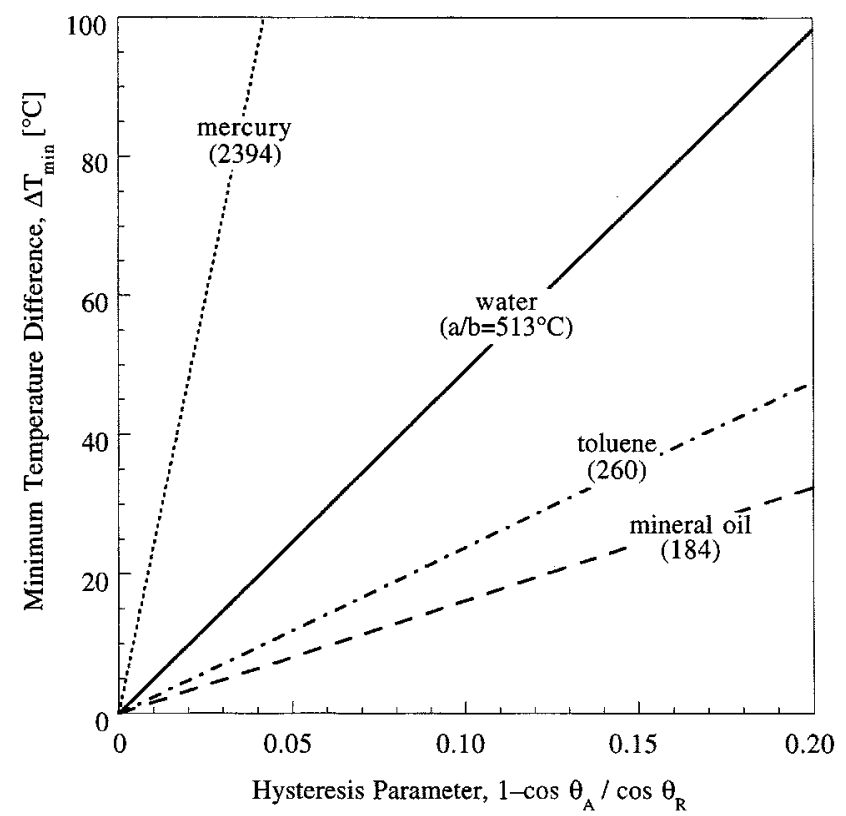

Figure 17. Effect of contact angle hysteresis $\left(1-\cos \theta_{A}\right)$ $\left.\cos \theta_{R}\right)$ on the minimum temperature difference required to initiate TCP $\left(\Delta T_{\min }\right)$.

The minimum temperature difference is also dependent upon the ratio of surface tension coefficients $a / b$. In this particular system the initial drop temperature $T_{0}$ is $22^{\circ} \mathrm{C}$.

In this particular example the initial drop temperature $T$. is $22^{\circ} \mathrm{C}$, the ratio of drop length to drop diameter $\mathrm{L} / \mathrm{d}$ is 100 , and $\theta_{\mathrm{A}}=\theta_{\mathrm{R}}=0^{\circ}$. 


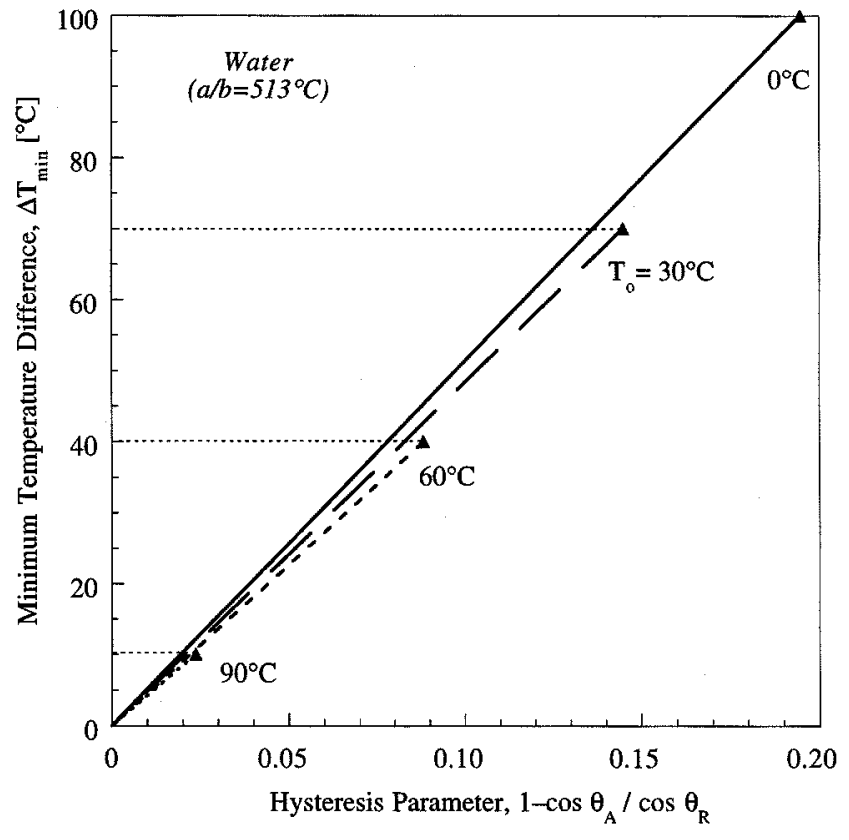

Figure 18. Effect of the initial temperature $T_{0}$ on the minimum temperature difference required to initiate TCP in water when contact angle hysteresis is present.

drop velocity

$$
\begin{aligned}
\cos \theta_{\text {Nujol }} & =-1.104 \nu-0.5826 \sqrt{v}+0.9642 \\
\cos \theta_{\text {oleic acid }} & =-0.2707 \nu-0.3956 \sqrt{v}+0.9013
\end{aligned}
$$

where $\theta$ is the advancing contact angle in degrees (the receding contact angles were all zero), and $\nu$ is the drop velocity in $\mathrm{cm} / \mathrm{s}$. Equations 19 and 20 were coupled with Eq. 12 and iteratively solved. The results, shown in Figure 19, reveal that the effect of the velocity dependence on contact angles is small at such low velocities (K wok et al., 1996).

Contact angles may also exhibit a slight negative temperature dependence, but the effect rarely exceeds $-0.1^{\circ} \mathrm{C}$ and is often much smaller (see Adamson, 1990). The effect on TCP is small since its effect is indirect through the cosine of the contact angle; consequently, a slight temperature dependence is dampened. Adamson (1990) lists the temperature dependence of water on several solid substrates; most values are on the order of $-0.01^{\circ} \mathrm{C}$. In the event of larger dependencies, a temperature-dependent contact angle could be incorporated into the TCP model.

Reducing $\mathrm{CAH}$. The magnitude of the contact angle hysteresis term in Eq. 12 can be reduced by altering the wetting behavior of a system by cleaning the surface, modifying the surface, or changing the surface roughness. Careful cleaning of a solid surface can reduce both contact angles (Leleah and Marmur, 1979) and contact angle hysteresis in a hydrophilic system ( $G$ aydos and Neumann, 1987). For instance, water is expected to perfectly wet $\left(\theta=0^{\circ}\right)$ a clean, smooth glass sur-

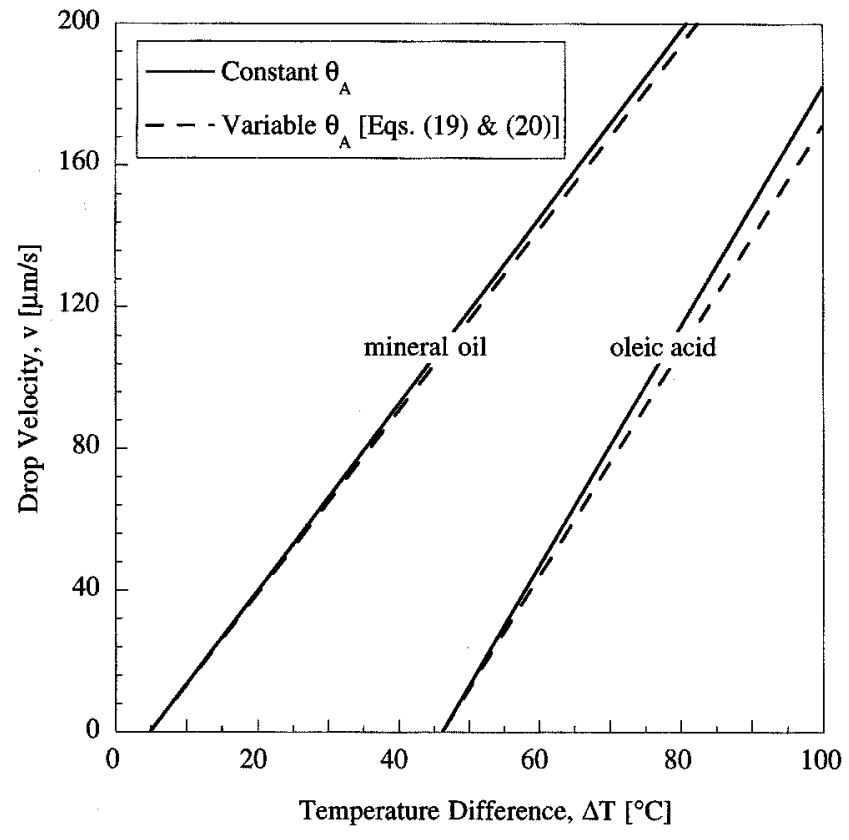

Figure 19. TCP velocity obtained for mineral oil (Nujol) and oleic acid using velocity dependent contact angles (Rose and Heins, 1962).

The results obtained with velocity dependent contact angles are compared to those obtained when the contact angles are held constant at their zero-velocity values. Note that circular channels were assumed, $\phi=\Delta \mathrm{P}_{\mathrm{e}}=0$, and $\mathrm{L} / \mathrm{d}=100$.

face, yet investigators such as Lelah and M armur (1979) have reported contact angles as large as $40^{\circ}$. In their study, they found that when a chromic acid cleaning solution was coupled with a 30 min heat treatment at $550^{\circ} \mathrm{C}$, they could reduce the contact angle of water on soda-lime glass from $40^{\circ}$ to essentially $0^{\circ}$.

Chemical modification of a surface has also been used to alter the wetting behavior in some systems ( $\mathrm{Kim}$ and Whitesides, 1997; Salay and Carmona-R ibeiro, 1998). For instance, $M$ enawit et al. (1984) reportedly changed the surface energy of water on soda-lime glass by modifying the glass surface with chemisorbed organochlorosilanes. By applying $5 \mathrm{mg} / \mathrm{mL}$ of t-butyl diphenylchlorosilane to the surface of glass rather than $0.1 \mathrm{mg} / \mathrm{mL}$, they were able to reduce the dynamic contact angle difference of water from $\theta_{\mathrm{A}} \approx 69^{\circ}$ and $\theta_{\mathrm{R}} \approx 55^{\circ}$ to $\theta_{\mathrm{A}} \approx 73^{\circ}$ and $\theta_{\mathrm{R}} \approx 71^{\circ}$. Consequently, $\Delta \mathrm{T}_{\min }$ would be reduced from $165^{\circ} \mathrm{C}$ to $45^{\circ} \mathrm{C}$.

Lastly, as mentioned earlier, surface roughness can cause contact angle hysteresis in a system. A study performed by J ohnson and Dettre (1964) revealed that contact angle hysteresis produced using water, methylene iodide, and hexadecane on "rough" solids was much lower than on solids classified as "smooth." For example, water on tetrafluoroethylene (TFE)-methanol telomer wax surfaces "smoothed" by heat treatments gave advancing and receding angles of $111^{\circ}$ and $95^{\circ}$, respectively $\left(\Delta \mathrm{T}_{\min }=332^{\circ} \mathrm{C}\right)$. "R ough" surfaces (no heat treatments) of identical composition, however, yielded advancing and receding angles of $159^{\circ}$ and $157^{\circ} \mathrm{C}$, respectively. $\Delta T_{\min }$ in this improved hydrophobic system would be $6^{\circ} \mathrm{C}$. 


\section{Supplementing temperature-induced pressures}

If the contribution of contact angle hysteresis to TCP exceeds that from temperature (that is, if $\Delta T_{\min }>\Delta \mathrm{T}$ in $\mathrm{Eq}$. 12 ), then additional measures can be employed to supplement the temperature-difference driving force. Possible supplements include using gravity, externally applied pressures and converging channels.

To more clearly isolate these terms, Eq. 12 was made dimensionless. The maximum capillary pressure difference from Eq. 8 with $\theta=0^{\circ}$ was used to de-dimensionalize $\Delta P$; this characteristic $\Delta P$ was coupled with $\mathrm{Eq} .6$ to determine a characteristic TCP velocity and that velocity was used to dedimensionalize $\nu$

$\nu_{\max }=\frac{\mathrm{Gd} \sigma_{\mathrm{o}}}{\mathrm{SL} \mu_{\mathrm{o}}} \quad \Rightarrow \quad \bar{\nu}=\frac{\nu}{\nu_{\max }}=\left(\frac{\mathrm{S}}{\mathrm{G}}\right)\left(\frac{\mathrm{L}}{\mathrm{d}}\right)\left(\frac{\mu_{\mathrm{o}}}{\sigma_{0}}\right) \nu$

$\mathrm{T}_{\max }=\frac{\mathrm{a}}{\mathrm{b}}, \mathrm{T}_{\min }=\mathrm{T}_{0} \Rightarrow \overline{\mathrm{T}}=\frac{\mathrm{T}-\mathrm{T}_{\min }}{\mathrm{T}_{\max }-\mathrm{T}_{\min }}=\frac{\mathrm{T}-\mathrm{T}_{0}}{\mathrm{a} / \mathrm{b}-\mathrm{T}_{0}}$

$\Delta \mathrm{P}_{\max }=\frac{\mathrm{G} \sigma_{0}}{\mathrm{~d}} \quad \Rightarrow \Delta \overline{\mathrm{P}}_{\mathrm{e}}=\frac{\Delta \mathrm{P}_{\mathrm{e}}}{\Delta \mathrm{P}_{\max }}=\frac{\Delta \mathrm{P}_{\mathrm{e}} \mathrm{d}}{\mathrm{G} \sigma_{0}}$

where $T$ is the temperature at the drop end being heated, $T_{0}$ is the initial drop temperature defining the liquid parameter

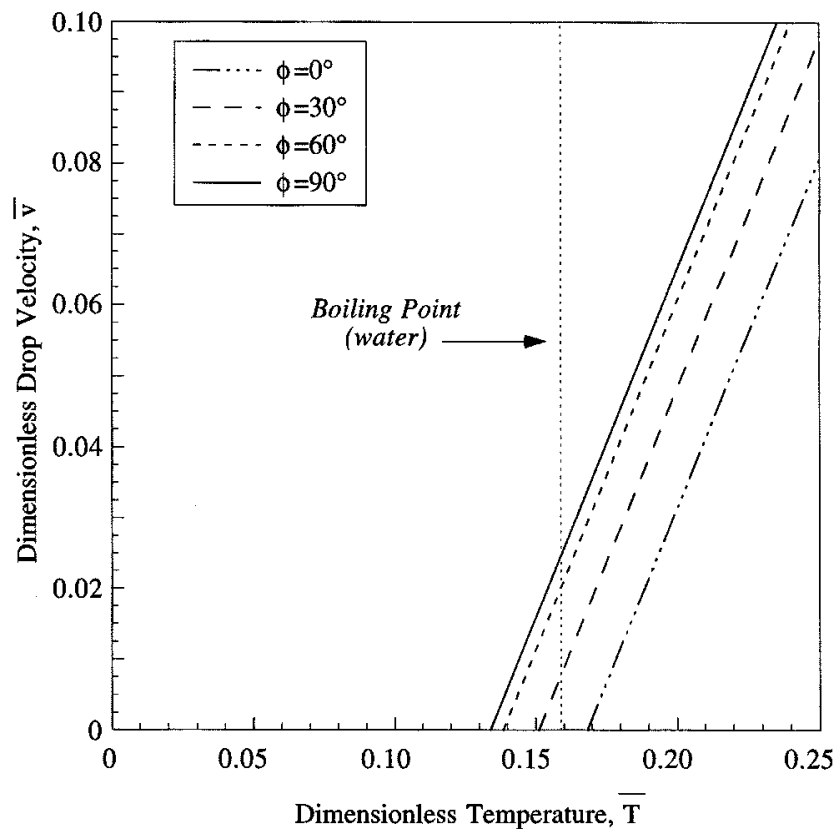

Figure 20. TCP of water assisted by gravity when contact angle hysteresis would normally prevent drop motion.

The contact angles used in this example are $\theta_{\mathrm{A}}=35^{\circ}$ and $\theta_{\mathrm{R}}=10^{\circ} . \phi=0$ indicates a horizontal channel while $\phi=90$ indicates a vertical channel. values, and $T_{\max }$ is $\mathrm{a} / \mathrm{b}$ - the zero surface tension temperature according to $\mathrm{Eq}$. 5 (typically unattainable but mathematically more convenient to use than $T_{b}$ ). Note that $\bar{T}=0$ when $T_{R}=T_{A}$. R earranging Eqs. 21-23 and substituting them into $\mathrm{Eq} .12$ yields the following dimensionless TCP velocity for a hydrophilic system

$$
\bar{\nu}=\cos \theta_{\mathrm{R}}\left(\overline{\mathrm{T}}_{\mathrm{R}}-\overline{\mathrm{T}}_{\min }\right)+\Delta \overline{\mathrm{P}}_{\mathrm{e}}+\mathrm{Bo}^{\prime}
$$

where

$$
\overline{\mathrm{T}}_{\min }=1-\frac{\cos \theta_{\mathrm{A}}}{\cos \theta_{\mathrm{R}}}
$$

and $\mathrm{Bo}^{\prime}$ is a modified Bond number that defines the contribution of gravity to TCP

$$
\mathrm{Bo}^{\prime}=\frac{\rho \mathrm{dL} g \sin \phi}{\mathrm{G} \sigma_{\mathrm{o}}}
$$

Note that Eq. 26 is slightly different from the Bond number shown in Eq. 1. The characteristic length scales for the gravity and surface tension contributions are different; the gravity contribution is based upon the drop length, while the surface tension contribution is based upon the channel height.

For gravity to sufficiently counter contact angle hysteresis, this modified Bond number, Bo', combined with the temperature term must be greater than the hysteresis term, that is

$$
\mathrm{Bo}^{\prime}+\overline{\mathrm{T}}_{\mathrm{R}} \cos \theta_{\mathrm{R}}>\overline{\mathrm{T}}_{\min } \cos \theta_{\mathrm{R}} \text {. }
$$

Consider an aqueous system where $d=0.01 \mathrm{~cm}, L=1 \mathrm{~cm}$, $\theta_{\mathrm{A}}=35^{\circ}$, and $\theta_{\mathrm{R}}=10^{\circ}$. Without the assistance of gravity (horizontal channel), contact angle hysteresis makes TCP inoperable because the dimensionless temperature needed for drop motion exceeds the boiling point of water (Figure 20). By orienting the channel vertically $(\phi=0)$, however, the modified $B$ ond number increases to 0.0337 ; when combined with the dimensionless temperature, the pair is sufficient to overcome contact angle hysteresis. If the drop's diameter and length were to decrease by an order of magnitude each, then the modified Bond number correspondingly decreases by a factor of 100 and would render gravity negligible. Consequently, gravity assisted TCP may be limited to relatively large channel systems on the order of a millimeter in diameter. A Iternatively, a centrifugal field can be used to increase $\mathrm{g}$ by several orders in magnitude but may be cumbersome to implement.

U nlike gravity, which is limited by a system's orientation and dimensions, externally applied pressures can be used to offset any level of contact angle hysteresis. The applied pressure needed to offset hysteresis in a horizontal drop can be found by setting $\mathrm{Eq} .24$ equal to zero and solving for $\Delta \overline{\mathrm{P}}_{\mathrm{e}}$ when the drop is at a uniform temperature

$$
\Delta \overline{\mathrm{P}}_{\mathrm{e}}=-\cos \theta_{\mathrm{R}}\left(\overline{\mathrm{T}}_{\mathrm{R}}-\overline{\mathrm{T}}_{\min }\right)
$$




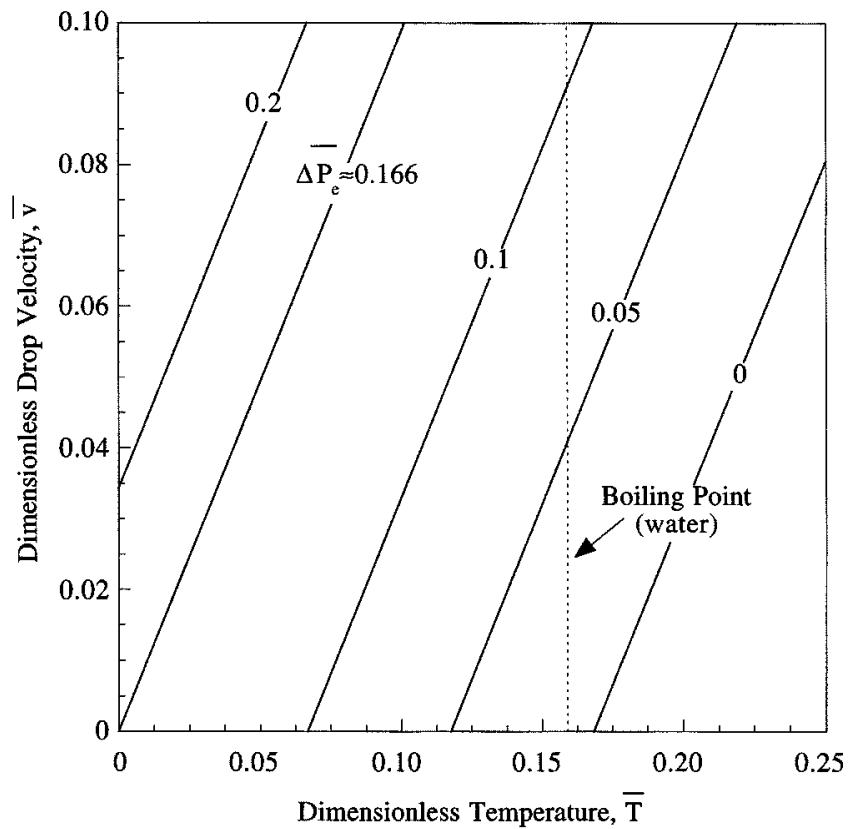

Figure 21. TCP of water assisted by an externally applied pressure $\Delta \bar{P}_{\mathrm{e}}$ when contact angle hysteresis would normally prevent drop motion. The contact angles used in this example are $\theta_{\mathrm{A}}=35^{\circ}$ and $\theta_{\mathrm{R}}=10^{\circ}$.

A pplying $\Delta \bar{P}_{\mathrm{e}}$ from $\mathrm{Eq} .28$ to a drop creates a situation similar to when contact angle hysteresis is not present-any nonzero temperature difference will initiate TCP. Figure 21 contains results for an aqueous system where $\theta_{\mathrm{A}}=35^{\circ}$ and $\theta_{\mathrm{R}}=10^{\circ}$. N otice that even with a rather large degree of contact, angle hysteresis TCP can be effectively utilized if a small external pressure, equal to that given by Eq. 28, is applied across the drop. For this system, $\Delta \bar{P}_{\mathrm{e}}=0.166$ corresponds to $0.0698 \mathrm{psi}(0.481 \mathrm{kPa})$ in a $0.01 \mathrm{~cm}$ diameter circular channel.

Converging channels are a final alternative to supplementing the temperature driving force in TCP when contact angle hysteresis is too large. A reduction in the channel diameter at the advancing interface of a hydrophilic drop will itself generate a pressure difference within the drop (de Nevers, 1970; Legait, 1983). This diameter-induced pressure difference compensates for the opposition to TCP by contact angle hysteresis. If the capillary is horizontal and at uniform temperature, then the pressure difference created by the converging channel can be found using Eq. 8. By setting Eq. 8 equal to zero, we can obtain the ratio of advancing to receding capillary diameters needed to balance contact angle hysteresis

$$
\epsilon=\frac{d_{A}}{d_{R}}=\frac{\cos \theta_{A}}{\cos \theta_{R}} .
$$

The shape of a converging channel described by Eq. 29 can be determined by assuming the drop is shaped as a section of a cone (frustum), displacing the drop one length at a time, and, finally, determining its shape at the new position using $\epsilon$ and the drop's volume. After n-moves of one drop length each, the drop dimensions at the nth position are

$$
\begin{gathered}
\frac{d_{n}}{d_{0}}=\epsilon^{n} \\
\frac{L_{n}}{L_{0}}=\epsilon^{-2 n}
\end{gathered}
$$

where $d_{0}$ is the diameter of the receding end of the drop in its initial position, $L_{0}$ is the initial drop length, and $d_{n}$ and $L_{n}$ are the drop diameter and length, respectively, at the receding end after n-movements. U sing Eq. 31, the axial channel position for the receding end of the drop $x_{n}$ can be found by summing the drop lengths resulting from all previous drop movements

$$
\begin{array}{r}
x_{n}=\sum_{i=1}^{i=n} L_{i-1}=L_{0}\left(1+\frac{1}{\epsilon^{2}}+\frac{1}{\epsilon^{4}}+\frac{1}{\epsilon^{6}}+\cdots+\frac{1}{\epsilon^{2(n-1)}}\right) \\
=L_{\circ}\left(\frac{\epsilon^{-2 n}-1}{\epsilon^{-2}-1}\right) .
\end{array}
$$

Substitution of $\mathrm{Eq}$. 30 into $\mathrm{Eq}$. 32 reveals a general expression relating channel diameter to channel position for a converging circular channel that satisfies Eq. 29 for a drop located at any position, $x$, in the channel

$$
\frac{d}{d_{0}}=\left[1+\left(\epsilon^{-2}-1\right) \frac{x}{L_{0}}\right]^{-1 / 2}
$$

A similar development for a converging rectangular or slit channel of constant width yields

$$
\frac{d}{d_{0}}=\left[1+\left(\epsilon^{-1}-1\right) \frac{x}{L_{0}}\right]^{-1} .
$$

The general nature of Eqs. 33 and 34 can be verified by integrating them between the ends of a drop whose interfaces satisfy Eq. 29. The resulting drop volume for an arbitrary channel position equals the volume for a drop in the initial channel position defined by $x=0$ and $x=L_{0}$. Note that channels with step-height changes can also be used for specific applications.

Knowing the wetting characteristics $\epsilon$ of a particular system, a converging channel that balances contact angle hysteresis can be designed to assist TCP using Eq. 33 or 34. The greater the contact angle hysteresis, the greater the initial decreases in channel diameter as shown in Figure 22. A Iternatively, Figure 23 shows the shape of a channel as it varies with initial drop length. The smaller the initial drop length, the greater the initial rate at which a channel converges. As the drop moves along the channel, however, its length increases and the channel eventually converges at a near constant rate. Note that, if a channel converges too rapidly, the drop spontaneously moves without a temperature difference. 


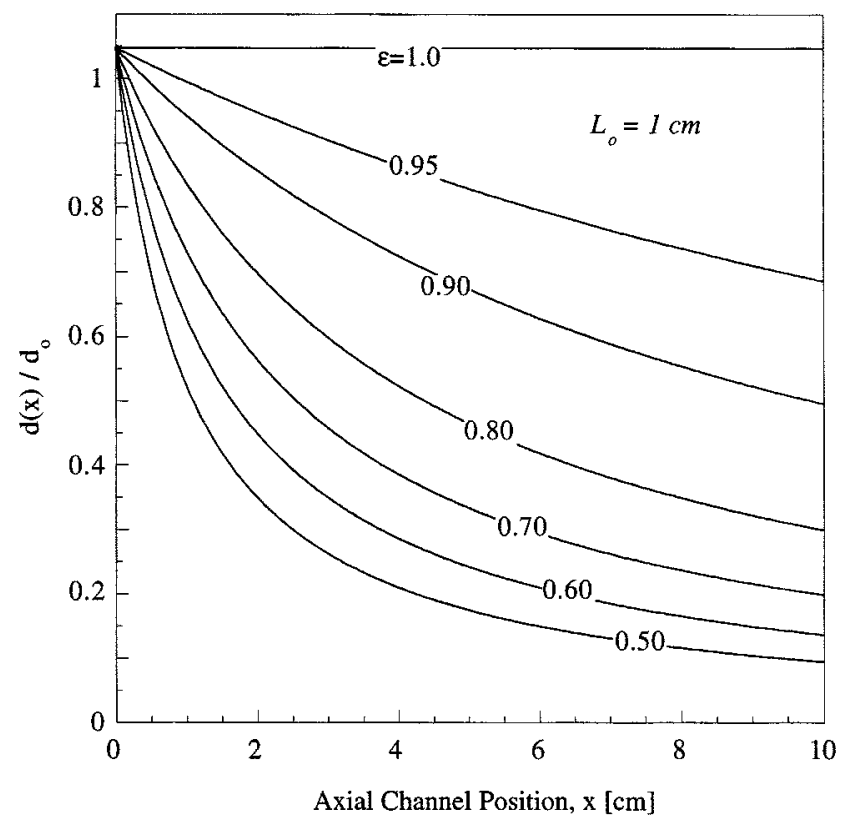

Figure 22. Radius of a converging circular channel needed to exactly offset contact angle hysteresis with initial drop length $L_{o}$ of $1 \mathrm{~cm}$.

The degree of convergence is dependent upon the wetting parameter $\epsilon$, which equals $\cos \theta_{\mathrm{A}} / \cos \theta_{\mathrm{R}}$.

\section{Conclusions}

A nonmechanical, thermocapillary pumping (TCP) mechanism was developed for moving discrete drops of liquid within micron-scale flow channels. The mechanism uses surface tension differences, induced by heating, to create a capillary pressure imbalance for drop motion. To study TCP behavior, an expression was developed for steady-state TCP velocity for Newtonian fluids, revealing that TCP velocity is proportional to the difference in temperature between the drop ends. The proportionality constant contains contributions from the channel shape, the liquid viscosity, the liquid's surface tension temperature coefficient, the dimensions of the drop, and the degree of contact angle hysteresis in the system.

Contact angle hysteresis $(\mathrm{CAH})$ reduces the temperatureinduced driving force of TCP, thereby introducing a minimum temperature difference requirement for drop movement $\Delta T_{\min }$. This minimum temperature difference is a function of the hysteresis parameter $1-\cos \theta_{A} / \cos \theta_{R}$. The greater the degree of hysteresis, the higher the minimum temperature difference needed to initiate drop movement. When contact angle hysteresis becomes so large that it causes a drop to boil before moving, then strategies can be used to supplement TCP. These strategies include using either converging channels, a small external pressure to assist TCP, or using surface modifications to reduce contact angle hysteresis in the system.

Experimental TCP results obtained for mineral oil agree with predictions made based on the presented theory. The data show a linearly increasing velocity dependence with temperature difference as predicted by the theory. Further-

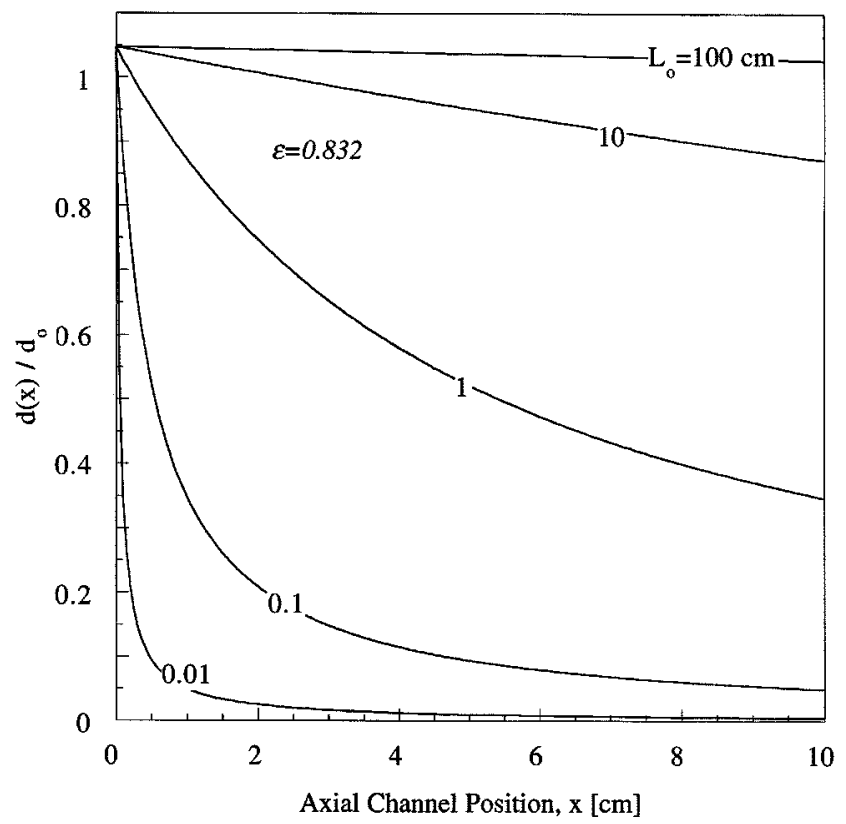

Figure 23. Radius of converging circular channel needed to exactly offset contact angle hysteresis with $\theta_{A}=35^{\circ}$ and $\theta_{R}=10^{\circ}(\epsilon=0.832)$.

The degree of convergence is dependent upon the initial drop length $L_{0}$.

more, the data verified that a nonzero minimum temperature difference was required to overcome contact angle hysteresis in the system. Theoretical TCP predictions made using an experimentally determined shape constant and measured contact angles matched the experimental results within the range of experimental uncertainty. Experiments performed in rectangular capillary channels also suggest that there is not an end effect associated with drops of varying length.

Thermocapillary pumping (TCP) offers a simple mechanism for moving drops of liquid within micron-scale channels. The advantage of TCP is its ability to locally control the movement of a single liquid drop rather than a continuous liquid stream. Furthermore, since TCP relies on simple interface heating, devices incorporating TCP can be easily constructed. These advantages make TCP a promising candidate for microfabricated chemical analysis devices that require precisely defined sample volumes and that strive for a simple method for achieving system integration.

\section{Acknowledgments}

The authors would like to thank David T. Burke (H uman Genetics), Carlos $\mathrm{H}$. M astrangelo (Electrical Engineering and Computer Science), and Brian N. Johnson (Chemical Engineering) at the U niversity of $\mathrm{M}$ ichigan for their advice and assistance. This research is part of a collaborative effort to develop microfabricated D NA analysis systems and is funded by the $N$ ational Institutes of $H$ ealth ( $G$ rant R 01-H G 01044).

\section{Literature Cited}

A nderson, R. C., G. J. Bogdan, Z. Barniv, T. D. Dawes, J. Winkler, and K. Roy, "M icrofluidic Biochemical A nalysis Systems," Trans- 
ducers '97: Int. Conf. on Solid-State Sensors and Actuators, 2, 477 (1997).

A blett, R ., "A $n$ Investigation of the A ngle of Contact between Paraffin W ax and Water," Phil. Mag., 46, 244 (1923).

A damson, A. W., Physical Chemistry of Surfaces, 5th ed., Wiley, N ew Y ork, p. 395 (1990).

Bart, S. F., L. S. Tarrow, M. M ehregany, and J. H. Lang, "M icrofabricated Electrohydrodynamic Pumps," Sensors and Actuators A21-A23, 193 (1990).

Bartell, F. E., and J. W. Shepard, "Surface R oughness as R elated to H ysteresis of Contact A ngles. I. The System Paraffin-W ater-A ir," J. Phys. Chem., 57, 211 (1953).

Bartell, F. E., and P. H. Cardwell, "R eproducible Contact A ngles on $R$ eproducible $M$ etal Surfaces. I. Contact Angles of Water A gainst Silver and Gold," J. Amer. Chem. Soc., 64, 494 (1942).

Beni, G., and M. A. Tenan, "Dynamics of Electrowetting Displays," J. Appl. Physics, 52, 6011 (1981).

Bikerman, J. J., "Surface Roughness and Contact Angle," J. Phys. Chem., 54, 653 (1950).

Bird, R. B., W. E. Stewart, and E. N. Lightfoot, Transport Phenomena, Wiley, N ew Y ork, p. 46 (1960).

Brandon, S., A. Wachs, and A. M armur, "Simulated Contact A ngle $\mathrm{H}$ ysteresis of a Three-Dimensional D rop on a Chemically $\mathrm{H}$ eterogeneous Surface: A N umerical Example," J. Colloid Interf. Sci., 191 110 (1997).

Bretherton, F. P., "The M otion of Long Bubbles in Tubes," J. Fluid Mech., 10, 166 (1961).

Burke, D. T., M. A. Burns, and C. M astrangelo, "M icrofabrication Technologies for Integrating Nucleic A cid A nalysis," G enome Res. 7, 189 (1997).

Burns, M. A., B. N. J ohnson, S. N. Brahmasandra, K. H andique, J. R. Webster, M. K rishnan, T. S. Sammarco, P. N. M an, D. Jones, D. Heltsinger, C. H. M astrangelo, and D. T. Burke, "A $n$ Integrated Nanoliter DNA A nalysis Device," Science, 282(5388), 484 (1998).

Burns, M. A., C. H. M astrangelo, T. S. Sammarco, F. P. M an, J. R Webster, B. N. J ohnson, B. Foerster, D. Jones, Y. Fields, A. R Kaiser, and D. T. Burke, "M icrofabricated Structures for Integrated D N A A nalysis," Proc. Natl. Acad. Sci., USA, 93, 5556 (1996).

Cefa, J. J., D. A. Barrow, P. Woias, and E. Muller, "Integrated Chemical A nalysis M icrosystems in Space Life Sciences R esearch," J. Micromech. Microengin., 4, 172 (1994).

Collet, P., J. DeC oninck, F. D unlop, and A. R egnard, "D ynamics of the Contact Line: Contact A ngle Hysteresis," Phys. Rev. L ett., 79, 3704 (1997).

de Gennes, P. G., "W etting: Statics and Dynamics," Rev. Mod. Phys., 57, 827 (1985).

de Nevers, N., Fluid Mechanics, Addison-Wesley, London, p. 462 (1970).

Denn, M. M., Process Fluid Mechanics, Prentice-H all, Englewood Cliffs, NJ, p. 189 (1980)

D ussan, E. B., "On the Spreading of Liquids on Solid Surfaces: Static and Dynamic Contact Angles," Ann. Rev. Fluid Mech., 11, 371 (1979).

Effenhauser, C. S., A. Paulus, A. M anz, and H. M. Widmer, "HighSpeed Separation of Antisense Oligonucleotides on a Micromachined Capillary Electrophoresis Device," Anal. Chem., 66(18), 2949 (1994).

Elliott, G. E. P., and A. C. Riddiford, "D ynamic Contact A ngles: I The Effect of Impressed Motion," J. Colloid Interf. Sci., 23, 389 (1967).

Elliott, G. E. P., and A. C. R iddiford, "D ynamic Contact A ngles and R ates of A dsorption," Nature, 195, 795 (1962).

Fan, Z. H., and J. Harrison, "M icromachining of Capillary Electrophoresis Injectors and Separators on Glass Chips and Evaluation of Flow at Capillary Intersections," Anal. Chem., 66, 177 (1994).

Folta, J. A., N. F. Raley, and E. W. Heo, "D esign, Fabrication and Testing of a M iniature Peristaltic M embrane Pump," Tech. Digest IEEE Solid-State Sensors and Actuators Workshop, 186 (1992).

Fuhr, G., T. Schnelle, and B. Wagner, "Traveling Wave-D riven M icrofabricated Electrohydrodynamic Pumps for Liquids," J. Micromech. Microeng., 4, 217 (1994).

Gaydos, J., and A. W. N eumann, "The Dependence of Contact An- gles on D rop Size and Line Tension," J. Colloid Interf. Sci., 120, 76 (1987).

Green, D., ed., Perry's Chemical Engineers' Handbook, 6th ed., M cG raw-H ill, N ew Y ork, p. 5 (1984).

Gutoff, E. B., and C.E. K endrick, "D ynamic Contact A ngles," AIChE J., 28, 459 (1982)

$\mathrm{H}$ arley, J., and H. Bau, "Fluid Flow in Micron and Submicron Size Channels," IEEE Proc. on Micro Electro Mechanical Systems: An Investigation of Micro Structures, Sensors, Actuators, Machines and Robots, p. 25 (Feb. 1989).

H andique, K., B. P. Gogoi, D. T. Burke, C. H. M astrangelo, and M. A. Burns, "M icrofluidic Flow Control U sing Selective Hydrophobic Patterning," Proc. of SPIE Conf. on Micromachined Devices and Components, 3224, 185 (1997).

Hannoe, S., I. Sugimoto, K. Y anagisawa, and H. Kuwano, "Enhanced Chromatographic Performance of Silicon-M icromachined Capillary Column with Clean Structure and Interactive Plasma O rganic Films," Transducers '97: Int. Conf. on Solid-State Sensors and Actuators, 2, 515 (1997).

H arrison, D. J ., K. Fluri, K. Seiler, Z. Fan, C. S. Effenhauser, and A. $M$ anz, "M icromachining a M iniaturized Capillary ElectrophoresisBased Chemical Analysis System on a Chip," Science, 261, 895 (1993).

H iemenz, P. C., Principles of Colloid and Surface Chemistry, M arcel Dekker, New Y ork, p. 321 (1986).

Jasper, J. J., "The Surface Tension of Pure Liquid Compounds," J. Phys. Chem. Ref. Data, 1, 841 (1972).

J in, W., J. Koplik, and J. R. Banavar, "Wetting $H$ ysteresis at the M olecular Scale," Phys. Rev. L ett., 78(8), 1520 (1997).

Johnson, J r., R. E., and R. H. Dettre, "Contact A ngle H ysteresis: II. Contact A ngle M easurements on R ough Surfaces," Contact Angle, Wettability, and Adhesion, Advances in Chemistry No. 43, R. F. Gould, ed., A mer. Chem. Soc., p. 136 (1964).

Kim, E., and G. M. Whitesides, "Imbibition and Flow of Wetting Liquids in Noncircular Capillaries," J. Phys. Chem. B, 101, 855 (1997).

K wok, D. Y., R. Lin, M. M ui, and A. W. Neumann, "Low-R ate Dynamic and Static Contact Angles and the Determination of Solid Surface Tensions," Colloids Surfaces A: Physiochem. Eng. Aspects, 116, 63 (1996).

L ange's H andbook of Chemistry, 14th ed., J. A . Denn, ed., M cG rawHill, N ew Y ork (1992).

Legait, B., "Laminar Flow of Two Phases Through a Capillary Tube with V ariable Square Cross-Section," J. Colloid Interf. Sci., 96, 28 (1983).

Leleah, M. D., and A. M armur, "Wettability of Soda-Lime Glass: The Effect of Cleaning Procedures," Am. Ceram. Soc. Bull., 58, 1121 (1979)

M anz, A., C. S. Effenhauser, N. Burggrah, D. J . Harrison, K. Seiler, and K. Fluri, "Electroosmotic Pumping and Electrophoretic Separations for M iniaturized Chemical Analysis Systems," J. Micromech. Microeng., 4, 257 (1995).

Marmur, A., "Contact Angles in Constrained Wetting," Langmuir, 12, 5704 (1996).

Marshall, A., and J. Hodgson, "DNA Chips: An A rray of Possibilities," N ature Biotechnol., 16, 27 (1998).

M enawat, A., J. Henry, J r., and R. Siriwardane, "Control of Surface Energy of Glass by Surface R eactions: Contact A ngle and Stability," J. Colloid Interf. Sci., 101, 110 (1984).

M ichaels, A. S., and S. W. D ean, J r., "Contact A ngle R elationships on Silica A quagel Surfaces," I. Phys. Chem., 66, 1790 (1962).

Ngan, C. G., and E. B. Dussan, "On the Nature of the Dynamic Contact Angle: An Experimental Study," J. Fluid Mech., 118, 27 (1982).

N orthrup, M . A ., M . T. Ching, R . M . W hite, and R. T. W atson, "D N A A mplification with a M icrofabricated R eaction Chamber," 7th Int. Conf. on Solid-State Sensors and Actuators, Y okohama, Japan, $p$. 924 (1993).

Patel, S. V., M. DiBattista, J. L. G land, and J. W. Schwank, "Survivability of a Silicon-Based M icroelectronic G as-D etector Structure for High-Temperature Flow Applications," Sensors and Actuators B, 37, 27 (1996).

Probstein, R. F., Physiochemical Hydrodynamics: An Introduction, Butterworths, Boston, M A, p. 272 (1989). 
Ramsey, G., "DNA Chips: State of the A rt," Nature Biotechnol., 16, 40 (1997).

R ichter, M., P. W oias, and D. W eiß, "M icrochannel for A pplications in Liquid D osing and Flow R ate M easurement," Sensors and Actuators A, 62, 480 (1997).

R illaerts, E., and P. J 00s, "The D ynamic Contact A ngle," Chem. Eng. Sci., 35, 883 (1979).

R ose, W., and R. W. H eins, "M oving Interfaces and Contact A ngle R ate Dependency," J. Colloid Sci., 17, 39 (1962).

Salay, L. C., and A. M. Carmona-R ibeiro, "Synthetic Bilayer Wetting on $\mathrm{SiO}_{2}$ Surfaces," J. Phys. Chem. B, 102, 4011 (1998).

Schwartz, A. M., C. A. Rader, and E. Huey, "Resistance to Flow in Capillary Systems of Positive Contact A ngle," Contact Angle, Wettability, and Adhesion, Advances in Chemistry No. 43, R. F. Gould, ed., A mer. Chem. Soc., p. 250 (1964).

Shikhmurzaev, Y. D., "D ynamic Contact A ngles and Flows in Vicinity of M oving Contact Line," AIChE J., 42, 601 (1996).

Shoji, S., and M. Esashi, "M icroflow Devices and Systems," J. Micromech. Microengin., 4, 151 (1994).

Smits, J. G., "Piezoelectric M icropump with Three Valves Working Peristaltically," Sensors and Actuators, A21- A23, 203 (1990).

Srinivasan, R., I.-M . H sing, P. E. Berger, K. F. Jensen, S. L. Firebaugh, M. A. Schmidt, M. P. H arold, J. J. Lerou, and J. F. R yley, "M icromachined Reactors for Catalytic Partial Oxidation Reactions," AIChE J., 43(11), 3059 (1997).

Schwartz, L. W., and R. R. Eley, "Simulation of D roplet M otion on Low-E nergy and Heterogeneous Surfaces," J. Colloid Interf. Sci., 202, 173 (1998).

U rbanek, W., J. N. Zemel, and H. Bau, "An Investigation of the Temperature $D$ ependence of Poiseuille N umbers in M icrochannel Flow," J. Micromech. Microeng., 3, 206 (1993). van de Pol, F. C., H. T. C. van Lintel, M. Elwenspoek, and J. H. J. Fluitman, "A Thermopneumatic M icropump Based on M icro-Engineering Techniques," Sensors and Actuators, A21- A23, 198 (1990).

van der B erg, A., and P. Bergvald, eds., Micro Total Analysis Systems: Proc. $\mu$ TAS'94 Workshop, MESA R es. Inst., U niv. of Twente, The Netherlands, K luwer A cademic Publishers, Boston (1995).

van Lintel, H. T. G., "A Piezoelectric M icropump Based on M icromachining of Silicon," Sensors and Actuators, 15, 153 (1988).

Walton, R. M., H. Liu, J. L. G land, and J. W. Schwank, "R esistance Measurements of Platinum-Titania Thin Film Gas Detectors in U Itra-High V acuum (UHV) and Reactive Ion Etcher (RIE) Systems," Sensors and Actuators B, 41, 143 (1997).

W ebster, J., and C. H. M astrangelo, "L arge-V olume Integrated Capillary Electrophoresis Stage Fabricated U sing M icromachining of Plastics on Silicon Substrates," Transducers '97: 1997 Int. Conf. on Solid-State Sensors and Actuators, 2, 503 (1997).

West, G. D., "On the R esistance to the M otion of a Thread of M ercury in a Glass Tube," Proc. Roy. Soc., 86, 20 (1911).

$Y$ arnold, G. D., "The Motion of a M ercury Index in a Capillary Tube," Proc. Roy. Soc., 50, 540 (1938).

$Y$ arnold, R. D., and B. J. M ason, "The Angle of Contact Between Water and Wax," Proc. Roy. Soc., 62, 125 (1948).

Zengerle, A., A. Richter, and H. Sandmaier, "A Micro Membrane Pump with Electrostatic Actuation," Proc. IEEE MEMS, Travemunde, Germany, p. 19 (1992).

Manuscript received Feb. 17, 1998, and revision received Nov. 17, 1998. 